\title{
Sulfur dioxide and primary carbonaceous aerosol emissions in China and India, 1996-2010
}

\author{
Z. Lu ${ }^{1}$, Q. Zhang ${ }^{2}$, and D. G. Streets ${ }^{1}$ \\ ${ }^{1}$ Decision and Information Sciences Division, Argonne National Laboratory, Argonne, IL 60439, USA \\ ${ }^{2}$ Center for Earth System Science, Tsinghua University, Beijing 100084, China
}

Received: 30 June 2011 - Published in Atmos. Chem. Phys. Discuss.: 18 July 2011

Revised: 15 September 2011 - Accepted: 20 September 2011 - Published: 23 September 2011

\begin{abstract}
China and India are the two largest anthropogenic aerosol generating countries in the world. In this study, we develop a new inventory of sulfur dioxide $\left(\mathrm{SO}_{2}\right)$ and primary carbonaceous aerosol (i.e., black and organic carbon, BC and $\mathrm{OC}$ ) emissions from these two countries for the period 1996-2010, using a technology-based methodology. Emissions from major anthropogenic sources and open biomass burning are included, and time-dependent trends in activity rates and emission factors are incorporated in the calculation. Year-specific monthly temporal distributions for major sectors and gridded emissions at a resolution of $0.1^{\circ} \times 0.1^{\circ}$ distributed by multiple year-by-year spatial proxies are also developed. In China, the interaction between economic development and environmental protection causes large temporal variations in the emission trends. From 1996 to 2000, emissions of all three species showed a decreasing trend (by 9\%-17\%) due to a slowdown in economic growth, a decline in coal use in non-power sectors, and the implementation of air pollution control measures. With the economic boom after 2000, emissions from China changed dramatically. BC and OC emissions increased by $46 \%$ and $33 \%$ to $1.85 \mathrm{Tg}$ and $4.03 \mathrm{Tg}$ in $2010 . \mathrm{SO}_{2}$ emissions first increased by $61 \%$ to $34.0 \mathrm{Tg}$ in 2006 , and then decreased by $9.2 \%$ to $30.8 \mathrm{Tg}$ in 2010 due to the wide application of flue-gas desulfurization (FGD) equipment in power plants. Driven by the remarkable energy consumption growth and relatively lax emission controls, emissions from India increased by $70 \%, 41 \%$, and $35 \%$ to $8.81 \mathrm{Tg}, 1.02 \mathrm{Tg}$, and $2.74 \mathrm{Tg}$ in 2010 for $\mathrm{SO}_{2}, \mathrm{BC}$, and $\mathrm{OC}$, respectively. Monte Carlo simulations are used to quantify the emission uncertainties. The average $95 \%$ confidence intervals (CIs) of $\mathrm{SO}_{2}, \mathrm{BC}$, and $\mathrm{OC}$ emissions are estimated to be $-16 \%-17 \%,-43 \%-93 \%$, and $-43 \%-80 \%$
\end{abstract}

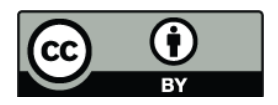

Correspondence to: $\mathrm{Z}$. Lu (zlu@anl.gov) for China, and $-15 \%-16 \%,-41 \%-87 \%$, and $-44 \%-$ $92 \%$ for India, respectively. Sulfur content, fuel use, and sulfur retention of hard coal and the actual FGD removal efficiency are the main contributors to the uncertainties of $\mathrm{SO}_{2}$ emissions. Biofuel combustion related parameters (i.e., technology divisions, fuel use, and emission factor determinants) are the largest source of OC uncertainties, whereas BC emissions are also sensitive to the parameters of coal combustion in the residential and industrial sectors and the coke-making process. Comparing our results with satellite observations, we find that the trends of estimated emissions in both China and India are in good agreement with the trends of aerosol optical depth (AOD) and $\mathrm{SO}_{2}$ retrievals obtained from different satellites.

\section{Introduction}

Atmospheric aerosols affect Earth's energy budget by scattering and absorbing solar radiation and by altering cloud properties and lifetimes. They also exert large influences on public health, air quality, weather, atmospheric chemistry, hydrological cycles, and ecosystems (e.g., Ramanathan and Carmichael, 2008; Streets et al., 2006, 2009). China and India are the two largest anthropogenic aerosol generating countries in the world. In the past decade, they have been identified as the two hot spots in terms of high aerosol optical depth (AOD) observed from space (Kharol et al., 2011; Prasad and Singh, 2007; van Donkelaar et al., 2008). The major active components of aerosols in these two countries are sulfate (of which the precursor is sulfur dioxide, $\mathrm{SO}_{2}$ ) and the primary carbonaceous aerosols black carbon (BC) and organic carbon (OC), together accounting for more than $60 \%$ of the AOD (Chin et al., 2009; Streets et al., 2009). From a global perspective, anthropogenic $\mathrm{SO}_{2}, \mathrm{BC}$, and $\mathrm{OC}$

Published by Copernicus Publications on behalf of the European Geosciences Union. 
emissions from China and India contribute $30 \%-40 \%$ of current global emissions (Bond et al., 2004, 2007; JRC/PBL, 2010; Smith et al., 2011), and have received the greatest attention from compilers of emission inventories.

Trends in anthropogenic emissions are closely tied to economic growth and technology development. Over the past two decades, China and India have undergone significant economic reform and have emerged as two of the world's fastest developing economies. Even during 2008-2009, China and India were the two nations that were least affected by the global economic recession, maintaining GDP growth rates of $9 \%$ and $6 \%$, respectively (IEA, 2010). In response to this economic growth and the rapid expansion in industrial production, energy consumption has increased accordingly. The share of energy use in China and India to the total world energy consumption increased from about $10 \%$ in 1990 to $21 \%$ in 2008 (IEA, 2010). Meanwhile, environmental legislation in both countries has promoted the introduction of new emission control and production technologies into the market, causing major changes in technology distributions as well as emission factors in relevant sectors. As a result, emissions of aerosols (and their precursors) have changed dramatically since the 1990s. Although some previous studies have reported $\mathrm{SO}_{2}, \mathrm{BC}$, and $\mathrm{OC}$ emissions from China and India, none of them have presented year-by-year trends with up-to-date activity rates and new technology penetration rates, especially for the period after 2005 (see Sect. 3.3.1). Therefore, the main purpose of this study is to use a consistent methodology to develop a comprehensive inventory of $\mathrm{SO}_{2}, \mathrm{BC}$, and $\mathrm{OC}$ emissions from China and India for the period 1996-2010 on the basis of time-dependent activity rates, technology penetration, emission factors, spatial proxies, monthly temporal distributions, etc.

There are sometimes disagreements between observations and model simulations (which make use of bottom-up emission databases), especially for carbonaceous aerosols, implying potentially large uncertainties in emission inventories. For example, Tan et al. (2004) suggested that increases in the TRACE-P emission inventory of particulate carbon by 60-90\% would bring modeled results into agreement with observations in China. Top-down estimates based on in-situ measurements of $\mathrm{BC}$ and $\mathrm{CO}$ during the INDOEX campaign yielded BC emissions of $2-3 \mathrm{Tg} \mathrm{yr}^{-1}$ for the South Asia continent (Dickerson et al., 2002), higher than bottom-up inventories $\left(<1 \mathrm{Tg} \mathrm{yr}^{-1}\right)$. Ramanathan and Carmichael (2008) estimated a global BC forcing of $0.9 \mathrm{~W} \mathrm{~m}^{-2}$ based on observation, three times higher than the average values of $0.3 \mathrm{~W} \mathrm{~m}^{-2}$ computed by bottom-up inventories-based general circulation models. Therefore, quantification of emission uncertainties is as important as estimating central values. Streets et al. (2003) estimated the uncertainty for each emitting subsector in the TRACE-P inventory by combining the coefficients of variation $(\mathrm{CV}$, the standard deviation divided by the mean) of the contributing factors. The uncertainties were then added linearly or in quadrature based on the judgments of dependent or independent correlations between different emitting subsectors. The confidence intervals (CIs) of this method are symmetric about the mean because all the underlying parameters are assumed to be normally distributed. However, the true probabilities of some parameters are asymmetric. Bond et al. (2004) reviewed the emission characteristics of various combustion sources, and found that the lognormal distribution is more appropriate for emission factors of carbonaceous aerosols. To obtain an asymmetric CI of each emitting source, they calculated the upper and lower CIs separately by treating the one-sided CI in the underlying distributions as uncertainties in a lognormal distribution and combining them in quadrature. In the past two decades, the Monte Carlo approach has been introduced into the emission inventory community to quantify the uncertainties of bottomup emission estimates. It has been gradually extended from an individual sector to multiple sectors in a country (Zhao et al., 2011, and references therein). Taking advantage of combining uncertainties of numerous parameters simultaneously and identifying the contribution of each parameter to the output's variance, we choose the Monte Carlo approach to evaluate the uncertainties of emissions estimated in this work.

The prime motivation of this study is to support the modeling work of the National Aeronautics and Space Administration's Goddard Space Flight Center (NASA/GSFC). NASA/GSFC is tasked to conduct a hindcast investigation of multi-decadal changes of atmospheric aerosols and their effects on surface radiation using the Goddard Chemistry Aerosol Radiation and Transport (GOCART) model in combination with aerosol data from satellite observations, ground-based measurements, and field experiments. The study is focused on the time period of the satellite era from 1980 to 2010. In our previous study, we have compiled a time-varying, comprehensive global emission dataset of aerosols and their precursors for the GOCART model for the period 1980-2006 (Chin et al., 2009; Streets et al., 2006, 2009). This dataset is considered reliable from 1980 to the mid-1990s, but thereafter updating is necessary to reflect new statistical data availability and the transformation of technology. The current work reported here addresses updated and extended emission datasets for China and India, two of the most important regions in the world. Subsequently, the work will be extended to all world regions.

In this study, we estimate the $\mathrm{SO}_{2}$ and primary carbonaceous aerosol (i.e., BC and OC) emissions from China and India for 1996-2010 using a detailed technology-based approach. Section 2 documents the methodology and data sets used in this work. The results, including estimated emissions, uncertainty analysis, comparison with other studies, gridded datasets, and seasonality of emissions are presented in Sect. 3. We also use satellite observations to verify our emission trends, the discussion of which is included in Sect. 4. Summary and conclusions are in Sect. 5. 


\section{Methodology and data sets}

\subsection{Estimation of $\mathrm{SO}_{2}$ and carbonaceous aerosol emissions}

\subsubsection{General methodology}

A technology-specific methodology is more appropriate and accurate for estimating emissions from anthropogenic sources because of the wide variation in emission rates for different types of processes and control technologies. In our previous work, we reported the development of detailed inventories of primary carbonaceous aerosol emissions for China, Asia, and the world (Bond et al., 2004; Streets et al., 2001, 2004). In particular, a detailed technology-based global inventory of primary $\mathrm{BC}$ and $\mathrm{OC}$ emissions was reported for the year 1996 (Bond et al., 2004). Using the annual fuel-use trends by world region and economic growth parameters included in the IMAGE model (National Institute for Public Health and the Environment, 2001), which was developed for the Intergovernmental Panel on Climate Change (IPCC), we further extended the 1996 inventory to an annual trend for the period 1980-2000 and adapted the methodology to calculate annual $\mathrm{SO}_{2}$ emissions over the same period (Streets et al., 2006, 2008, 2009).

In this study, a similar approach is adopted. The emission sources are categorized into five major sectors (i.e., power generation, industry, residential, transport, and open biomass burning) and more than $120 \mathrm{sector} / f u e l($ or product)/technology combinations, including both fuel combustion and non-combustion sources. Total emission $\left(E_{i, j}\right)$ for species $j$ and country $i$ is given by the following equation:

$$
E_{i, j}=\sum_{l} \sum_{m} A_{i, l, m}\left[\sum_{n} X_{i, l, m, n} \mathrm{EF}_{i, j, l, m, n}\right]
$$

where $l, m$, and $n$ represent the sector, the fuel/product type, and the technology type for combustion and industrial processes, respectively. A represents the activity rates, such as fuel consumption and material production, and $X$ represents the fraction of fuel/product for a sector that is consumed by a specific technology (i.e., $\sum X=1$ for each fuel/product and sector). EF is the net emission factor, and for sub-micrometer carbonaceous aerosols, it is given by:

$\mathrm{EF}_{\mathrm{BC}(\text { or OC) }}=\mathrm{EF}_{\mathrm{PM}} \cdot F_{1.0} \cdot F_{\mathrm{BC}}$ (or OC) $\cdot F_{\text {control }}$

where $\mathrm{EF}_{\mathrm{PM}}$ is the bulk particulate emission factor; $F_{1.0}$ is the fraction of the emissions with diameters smaller than $1 \mu \mathrm{m} ; F_{\mathrm{BC}}$ (or $F_{\mathrm{OC}}$ ) is the fraction of the $\mathrm{PM}_{1.0}$ (particles less than $1.0 \mu \mathrm{m}$ in aerodynamic diameter) that is $\mathrm{BC}$ (or $\mathrm{OC}$ ); and $F_{\text {control }}$ is the fraction of $\mathrm{PM}_{1.0}$ that penetrates the control device. For $\mathrm{SO}_{2}$ from fuel combustion sources, $\mathrm{EF}$ can be calculated by:

$\mathrm{EF}_{\mathrm{SO}_{2}}=2 \cdot S \cdot(1-\mathrm{SR}) \cdot\left(1-\eta_{k}\right)$ where $\eta_{k}$ is the removal efficiency of control technology $k ; S$ and SR are the sulfur content of fuel and sulfur retention in ash, respectively. Based on this framework, we estimated the $\mathrm{SO}_{2}$ and carbonaceous aerosol emissions in China and India for 1996-2010 by incorporating the time-dependent trends in activity rates, technology penetration, emission controls, coal sulfur content, etc.

\subsubsection{Uncertainty analysis}

Due to the various underlying probability distributions of input parameters, the uncertainties cannot be combined analytically. In this work, we use a Monte Carlo approach to determine the uncertainties in the emission estimates. The procedure is to generate a set of values of the random variables in accordance with specified probability distributions, so that a series of corresponding solutions is obtained. The methods of statistical estimation and inference can then be applied to such solutions to describe their uncertainties. For Monte Carlo simulations, specifying the probability distributions of the input parameters is a fundamental task. For parameters with adequate data and reported distributions, we applied them directly in our model, and for parameters with limited or no observation data, probability distributions were based on the authors' expert judgment. These will be discussed in detail in the following sections. All of the input parameters (e.g., activity rates, emission factor determinants) and their corresponding probability distributions were then incorporated into a Monte Carlo framework with the Crystal Ball software and at least 6000 valid simulations were performed. Unless specified otherwise, the term "uncertainty" in this article refers to a $95 \% \mathrm{CI}$ around the central estimate (i.e., mean).

\subsubsection{Activity rates}

Energy and fossil fuel consumption data for most of the sector/fuel/technology combinations were from the International Energy Agency (IEA, 2010), which provides information on 102 flows (e.g., imports, exports, and sectoral consumption) of 66 fuels. We separated and aggregated these activities based on the emission characteristics of each combustion process to fit the source types in our model (see Bond et al., 2004 for details). At present, 2008 is the latest year for which those data are available. Activity rates were therefore extrapolated from 2008 to 2010 based on national fast-track statistics. If no up-to-date data are available, values from the most recent year are used. Since probability distributions are not provided with official statistics, we applied normal distributions for all of the fossil fuel usage combinations. Generally, the uncertainties were assumed as follows: $10 \%$ for power generation, $20 \%$ for industrial and liquid fossil fuels in the residential sector, and $33 \%$ for transport and coal use in the residential sector. These values are based on a review of previous studies (Bond et al., 2004; Streets et al., 2003; 
Smith et al., 2011; Zhao et al., 2011). It was reported that the IEA statistical data (edition 2004) of coal consumption in China may be underestimated during 1996-2003, and are not recommended for use in emission inventory studies in China during this period (Akimoto et al., 2006). However, IEA revised China's historical coal consumption data in the current edition based on new economic surveys by the China National Bureau of Statistics (NBS) (IEA, 2010). Hence, IEA coal consumption statistics of China are used in this work. For India, there are no official statistics for coal consumption in the residential sector, and very little or no coal consumption was assumed in several previous Indian emission inventories (Parashar et al., 2005; Reddy and Venkataraman, 2002a). However, IEA reported that the residential sector contributes about $20-30 \%$ of the non-power-generation coal use (IEA, 2010). For this reason, uncertainties of $50 \%$ were assigned to both industrial and residential coal consumption in India. In India, a high gasoline price leads to the practice of fuel adulteration (i.e., mixing kerosene into gasoline). The fraction of kerosene in fuel can reach as high as $50 \%$, but the actual extent of this practice is unknown (Dickerson et al., 2002; Patra and Mishra, 2000). Dickerson et al. (2002) assumed that all spark-ignition engines burn $2 / 3$ gasoline and $1 / 3$ kerosene. Using the same assumption, we multiplied the on-road gasoline consumption in India by 1.5 , and assigned an uncertainty of $50 \%$ to it.

Historical biofuel consumption in China and India were obtained from other data sources. For China, the provincial consumption of biofuel was derived from the China Energy Statistical Yearbook (CESY) (NBS, 1998-2010), and the consumption patterns in rural areas were taken from Zhang et al. (2009a). For India, previous estimates of biofuel consumption contained large uncertainties due to the small sample sizes and outdated energy surveys carried out during 1985-1992 (e.g., Bond et al., 2004; Reddy and Venkataraman, 2002b; Streets et al., 2003; Yevich and Logan, 2003; Sinha et al., 1998). To address these drawbacks, Habib et al. (2004) developed a new method based on food consumption statistics and the specific energy requirement for food preparation, and estimated Indian biofuel consumption for cooking in year 2000. In this study, we followed a similar methodology, and extended it to an annual trend for the period 1996-2010. The probability distribution of biofuel use is probably not symmetric. Yevich and Logan (2003) examined both the range and the standard deviation of published per capita biofuel usage, and assessed uncertainties of $-40 \%$ to $+95 \%$ for biofuel consumption in Asia. Habib et al. (2004) estimated that the $95 \%$ CI of total biofuel consumption in India is $-35 \%-54 \%$ about the mean with lognormal distribution. Therefore, we generally assumed lognormal distributions for biofuel use for both China and India. The uncertainties (upper $95 \% \mathrm{CI}$ about the mean) are $46 \%, 74 \%$, and $86 \%$ for Indian fuelwood, dung-cake and crop waste, respectively (Habib et al., 2004), and $80 \%$ for biofuel use in China (authors' judgment).
Four types of open biomass burning are included: tropical forests, extra-tropical forests, savanna/grassland, and crop residue burning in fields. The national dry matter burned of forests and grassland were zonally aggregated according to the country boundaries of China and India from the Global Fire Emissions Database (GFED) version 3.1, which calculates fire emissions based on a revised version of the Carnegie-Ames-Stanford-Approach (CASA) biogeochemical model and improved satellite-derived estimates of area burned, fire activity, and plant productivity (van der Werf et al., 2010). The database provides the first global assessment of the contributions of different sources to total global fire emissions at $0.5^{\circ} \times 0.5^{\circ}$ spatial resolution for the 1997 2009 with a monthly time step. For years 1996 and 2010, we used average values of data between 1997 and 2009. Regarding the probability of open burning of each type of fire, normal distributions with year-specific uncertainties provided in the GFED v3.1 were assumed. Although GFED v3.1 contains fires from agricultural waste burning, these estimates are likely a lower bound, since the method for measuring burned area can only detect the relatively large fires (van der Werf et al., 2010). Therefore, we adopted a different approach for estimating the burning of crop residue in fields, using the product of the yield of different crops, the cropto-residue ratios, and the fraction of crop burnt in the field (Cao et al., 2006; Sahai et al., 2010; Venkataraman et al., 2006; Wang and Zhang, 2008). Crop production statistics were obtained from the China Agricultural Yearbook (Ministry of Agriculture of China, 1997-2009) and the India Agriculture Statistics at a Glance (Ministry of Agriculture of India, 1996-2010) for China and India, respectively. Crop-toresidue ratios and crop burnt fraction in the field were from Cao et al. (2006) and Wang and Zhang (2008) for China, and Sahai et al. (2010) and Venkataraman et al. (2006) for India. Derived from Sahai et al. (2010) and Zhao et al. (2011), normal distributions with uncertainties of $40 \%$ were assumed for crop waste burned in fields.

We followed Bond et al. (2004)'s method to estimate open waste burning of the two countries during 1996-2010. Total open waste combustion was calculated by multiplying per capita waste generation rates, urban populations (assume waste generation in rural areas is low in developing countries because goods are inherently recycled), and fraction of waste burned in urban areas. We acknowledge that our estimates of open waste burning are quite uncertain, and assign uncertainties of $200 \%$ to these estimates (Bond et al., 2004). For non-combustion emissions, industrial production levels were obtained from various sources, such as the China Industry Economy Statistical Yearbook (NBS, 1997-2010a) and the Handbook of Statistics on the Indian Economy (Reserve Bank of India, 2010). We applied normal distributions with uncertainties of $20 \%$ to these statistics based on expert judgment.

Figure 1 shows annual energy consumption by sector and fuel type in China and India between 1996 and 2010. 

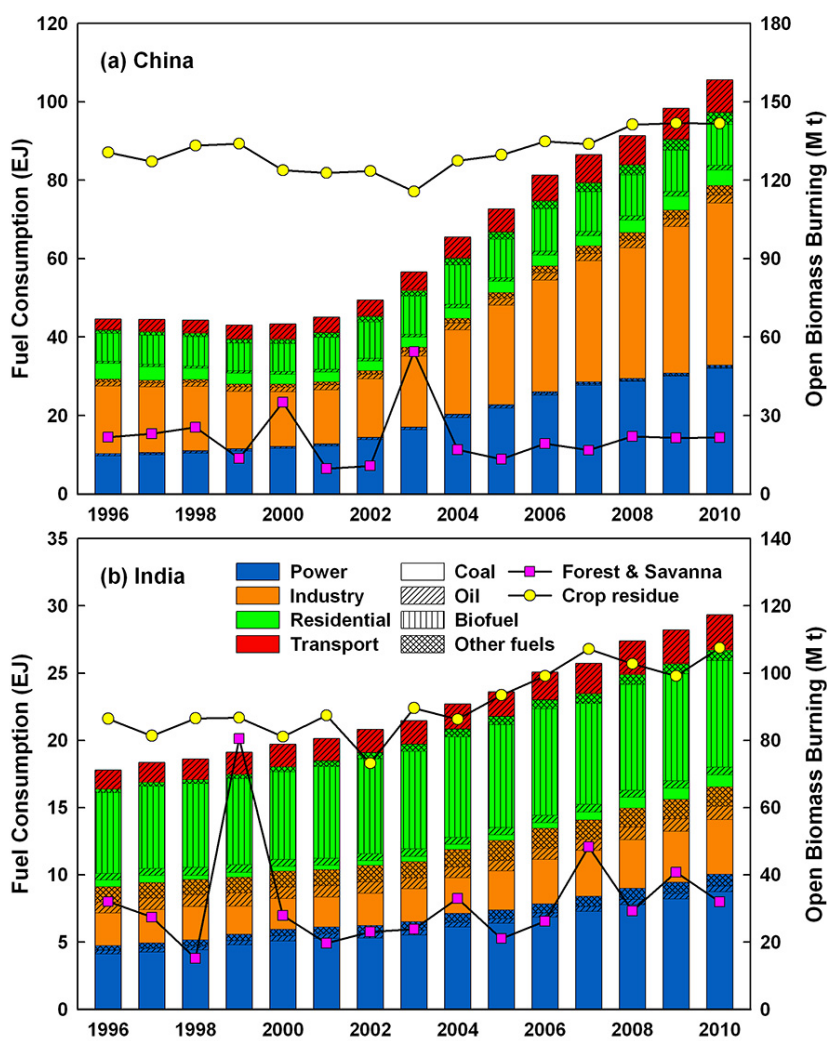

Fig. 1. Energy consumption by sector and fuel type, and biomass burned in (a) China and (b) India during 1996-2010.

Quantities of fuels were converted into energy equivalents using net calorific values supplied in IEA Energy Statistics (IEA, 2010) and the GAINS model (Klimont et al., 2009). Energy consumption in China remained relatively stable during 1996-2000 and then increased dramatically from $43.3 \mathrm{EJ}$ to 105.5 EJ during 2000-2010, with an annual growth rate of $9.3 \%$. On average, the highest sectoral consumption is in industry $(39 \%)$, followed by power plants $(29 \%)$, residential (24\%), and transportation (8\%). Different from China, the energy consumption in India continuously increased from $17.8 \mathrm{EJ}$ in 1996 to $29.3 \mathrm{EJ}$ in 2010 , with an annual growth rate of $3.6 \%$. Industry, power plants, residential, and transportation contribute $22 \%, 31 \%, 39 \%$, and $8 \%$ of the national energy consumption, respectively. Figure 1 also shows the amount of biomass burned in the two countries. Obviously, open biomass burning has significant interannual variability. The average dry mass burned in China and India during $1996-2010$ is $21.6 \mathrm{Mg} \mathrm{yr}^{-1}$ and $32.0 \mathrm{Mg} \mathrm{yr}^{-1}$ for forest and grassland, and $130.5 \mathrm{Mg} \mathrm{yr}^{-1}$ and $91.2 \mathrm{Mg} \mathrm{yr}^{-1}$ for agricultural waste.

\subsubsection{Technology divisions}

As shown in Eq. (1), we used parameter $X$ to divide the sector/fuel (or product) combinations into different technolo- gies. This procedure provides the ability to estimate emissions dynamically, because the change of emission factors over time can be represented as a change of technology penetration. This is very important for rapidly developing countries like China and India since new technologies are continuously coming into the market, causing dramatic changes in emission factors. For fuel use in the residential, power generation, and industry sectors, the application rates of different combustion technologies (or processing technologies for industrial products) and the distribution of emission control devices during 1996-2010 were compiled from a wide range of literature, such as Lei et al. (2011), Klimont et al. (2009), Lu et al. (2010), Streets et al. (2003), Reddy and Venkataraman (2002a, b), and Zhao et al. (2011). For the transportation sector, technologies refer to different vehicle types with different emission standards. In the present work, we classified on-road vehicles into four types, including light-duty gasoline vehicles, light-duty diesel vehicles, heavy-duty diesel vehicles, and motorcycles. Timedependent distribution of oil consumption between different vehicle/standard types was derived from He et al. (2005) and Wang et al. (2006) for China, and the GAINS-Asia model (Klimont et al., 2009) for India. For off-road vehicles and machinery, we directly tabulated the fuel use of ships, railroad locomotives, and agricultural vehicles from IEA statistics. We also took into account the effect of superemitters of each vehicle type, since they could contribute a large fraction of carbonaceous aerosol emissions to the transportation sector (Bond et al. 2004, and references therein), and relevant information was derived from the Speciated Pollutant Emission Wizard (SPEW)-Trend model (Yan et al., 2011).

It is difficult to directly quantify the uncertainties of technology divisions because (1) it is almost impossible to obtain the probability distribution and CI of $X$, and (2) the technology fractions in each fuel/product sector are highly correlated and should meet the constraint that $\sum X=1$. Alternatively, Bond et al. (2004) assigned the uncertainties in technology divisions by increasing the fraction of higher-emitting technologies so that they contribute an additional $10 \%$ of the total fraction, and decreasing the fraction of lower-emitting technologies by an equal amount. Here, we modified this method to generate random variables of technology fractions. For fuel/product with two technology divisions (of which fractions are $X_{1}$ and $X_{2}$ ), a uniform distribution was assumed to $X_{1}$ in the range of \pm 0.1 about the mean (i.e., $\left[X_{1, \text { mean }}-0.1, X_{1, \text { mean }}+0.1\right]$ ), while $X_{2}$ was calculated as $1-$ $X_{1}$. For fuel/product with three or more divisions (of which fractions are $X_{1}-X_{n}$ ), we assumed uniform distributions in the range of \pm 0.1 about the mean for both the highestemitting (i.e., $\left[X_{\text {high,mean }}-0.1, X_{\text {high,mean }}+0.1\right]$ ) and lowestemitting technology (i.e., $\left[X_{\text {low,mean }}-0.1, X_{\text {low,mean }}+0.1\right]$ ), and simply determined the variation ranges of the other technology fractions as $\pm\left(1-X_{\text {high }}-X_{\text {low }}-\sum X_{\text {other,mean }}\right) /(n-$ 2 ). If negative numbers were generated for any combination, this series of random variables was discarded. In addition, 
when we believe our understanding of a certain technology division is more uncertain, we alter the fraction by $0.3 \mathrm{in}$ stead of 0.1 (e.g., for coke making with/without controls and superemitter fractions in a vehicle fleet).

\subsubsection{Emission factors}

As shown in Eq. (3), the emission factor of $\mathrm{SO}_{2}$ is dependent on the fuel sulfur content $(S)$ and the sulfur retention ratio in ash (SR). For China, $S$ values of coal and oil consumed by combustion sources were derived from our previous work and recent literature (Klimont et al., 2009; Ohara et al., 2007; Zhao et al., 2008; Streets et al., 2003, 2006; Lu et al., 2010). The national average $S$ of coal in China was $1.10 \%$ in $1996,1.08 \%$ in 2000 , and $1.02 \%$ in 2005 . We used interpolation values to represent $S$ in each year during 1996-2005, and assumed the sulfur contents did not vary after 2005, because no reliable data are available. The $S$ of oil consumed in road transportation in China was determined from the national standards and the GAINS model, and it declined from $0.05 \%$ to $0.005 \%$ for gasoline and from $0.28 \%$ to $0.02 \%$ for diesel during 1996-2010. For India, the $S$ values of fossil fuels were based on the data reported by Reddy and Venkataraman (2002a) and the GAINS model (Klimont et al., 2009). The mean $S$ of coal in India was determined to be $0.55 \%$, and that of gasoline and diesel for road transportation decreased from $0.18 \%$ to $0.08 \%$ and from $0.47 \%$ to $0.05 \%$ between 1996 and 2010, respectively. Regarding the probability distributions of $S$, we assumed normal distributions with uncertainties of $20 \%$ for all fossil fuels (Smith et al., 2011; Streets et al., 2003). The SR ratio for coalfired power plants in China was assumed to be $10 \%$ with beta distributions (95\% CI: 7.5\%-14\%) based on field measurements by Zhao et al. (2011). For other sectors, SR ratios were set at $5 \%-45 \%$, depending on the process type, combustion technology, and coal type. Due to the lack of information on field measurements, uniform distributions were assumed in the range of minimum and maximum values reported in the literature (Klimont et al., 2009; Ohara et al., 2007; Reddy and Venkataraman, 2002a; Smith et al., 2011; Streets et al., 2003; Zhao et al., 2011). The $\mathrm{SO}_{2}$ emission factors of biofuel combustion were based on the measurements by Habib et al. (2004), and we assumed normal distributions with uncertainties provided in their work. For $\mathrm{SO}_{2}$ emission factors of industrial processes, values in the GAINS model were used and normal distributions with uncertainties of $40 \%$ were applied based on the authors' judgment (Smith et al., 2011; Streets et al., 2003).

The emission factor of $\mathrm{SO}_{2}$ is also strongly dependent on the application rate and the removal efficiency of fluegas desulfurization (FGD) devices. FGD application rates of power plants in China were estimated by the ratio of average FGD installed capacity to the average capacity of power plants in each year. Relevant data were obtained from the China Ministry of Environmental Protection (MEP) and the
China Electric Power Yearbook (State Electricity Regulatory Commission, 2000-2009). Ideally, the $\mathrm{SO}_{2}$ removal efficiency of FGD can reach $95 \%$ (Zhao et al., 2011). However, actual operations rarely reach this (Xu et al., 2009). In the present work, symmetrically triangular distributions were assumed for the actual removal rate of FGD. We set the official data as the most likely value, and the ideal value of $95 \%$ as the maximum to build the triangular distribution function. For example, the official data from the China MEP reported that $73.2 \%$ of $\mathrm{SO}_{2}$ was removed from coal-fired power plants equipped with FGD in 2007 (MEP, 2009). Thus, the mean value of removal efficiency of FGD in 2007 was $73.2 \%$ with a triangular distribution in the range of $51.4 \%$ to $95 \%$. For Indian power plants, the application rate of FGD is very low $(<2 \%)$ (Reddy and Venkataraman, 2002a) since Indian coal has a much lower sulfur content. Therefore, the effect of FGD on $\mathrm{SO}_{2}$ emissions from India was not considered in this study.

Emission factor determinants of $\mathrm{BC}$ and $\mathrm{OC}$ for each of the sectors, fuels, and technologies in Eq. (2) were updated in collaboration with Professor Tami Bond on the basis of their previous work (Bond et al., 2004). In addition, we introduced minor adjustments after reviewing some new countryspecific measurements of emission factors for biofuel combustion in India (Parashar et al., 2005; Venkataraman et al., 2005; Habib et al., 2008) and China (Cao et al., 2006; Li et al., 2009), and residential coal combustion in China (Chen et al., 2009; Zhi et al., 2008). Regarding the uncertainties of emission factor determinants, Bond et al. (2004) reviewed the $\mathrm{BC}$ and $\mathrm{OC}$ emission characteristics of various combustion sources comprehensively, and incorporated the information (central estimate, lower and upper bounds, etc.) of each parameter into a program called Speciated Particulate Emissions Wizard (SPEW). For the bulk particulate emission factors $\left(\mathrm{EF}_{\mathrm{PM}}\right)$, Bond et al. (2004) found that the lognormal distribution provides a reasonable fit to the measured data. Hence, we assumed $\mathrm{EF}_{\mathrm{PM}}$ is lognormally distributed with $95 \% \mathrm{CI}$ at the lower and upper bounds provided in SPEW. For other parameters $\left(F_{1.0}, F_{\mathrm{BC}}, F_{\mathrm{OC}}\right.$, and $\left.F_{\text {control }}\right)$, uniform distributions in the range of lower and upper bounds provided in SPEW were assumed due to the limited data availability.

Andreae and Merlet (2001) critically reviewed and evaluated the emission factors of trace gases and aerosols from open biomass burning. Since not enough data are available, uncertainties of $\mathrm{SO}_{2}, \mathrm{BC}$, and $\mathrm{OC}$ emission factors for open burning of forests, grasslands and agricultural wastes were characterized by the means and standard deviations of their data, assuming a normal distribution.

\subsection{Spatial allocation method}

We used a "top down" approach to transform country-level emissions to gridded datasets. Sectoral emissions (excluding emissions from power plants and forest and savanna burning) were first allocated to each province (or state), 
and then distributed on a $0.1^{\circ} \times 0.1^{\circ}$ grid using appropriate year-by-year spatial proxies. For the first step, emission information at provincial (or state) level was obtained from Lu et al. (2010) and Lei et al. (2011) for China, and the GAINS model (Klimont et al., 2009) for India. We generated year-specific allocation factors at a resolution of a $0.1^{\circ} \times 0.1^{\circ}$ by using various types of Geographical Information System (GIS) datasets: (1) total population data were extracted from the LandScan Global Population Data Set developed by Oak Ridge National Laboratory for the period 2004-2008 (ORNL, 2009), and from the History Database of the Global Environment (HYDE) developed by the Netherlands Environmental Assessment Agency for the period before 2004 (Goldewijk et al., 2011); (2) urban and rural population data were developed based on the total population datasets and information from the Global Rural-Urban Mapping Project (GRUMP) (CIESIN et al., 2004); (3) cropland cover data during 1996-2007 were obtained from an updated version of the Global Cropland Dataset (Ramankutty and Foley, 1999); (4) road networks were extracted from the Digital Chart of the World (DMA, 1993); (5) China's industrial GDP at county level during 2000-2008 were obtained from the China County Statistical Yearbook (NBS, 2001-2009). The allocation rules are: (1) road networks for on-road transportation emissions, (2) cropland cover for emissions from agricultural waste burning and off-road tractors, (3) China's industrial GDP by county for industrial emissions in China, (4) EDGAR 4.1 (JRC/PBL, 2010) industrial gridded emissions for industrial emissions in India, (5) rural population for residential biofuel combustion, (6) urban population for emissions from residential coal-fired boilers and open waste burning, and (7) total population for all other area sources. It should be noted that assessing the uncertainty in the spatial allocation is beyond the scope of this study and was not considered.

Emissions from biomass burning and coal-fired power plants were treated separately in this study. For open biomass burning from forest and savanna, gridded data from GFED v3.1 (van der Werf et al., 2010) were directly used. For China's coal-fired power sector emissions, year-by-year gridded data were obtained from our collaborators at Tsinghua University (Zhang et al., 2009b; Zhao et al., 2008). They were generated from a detailed, unit-based inventory specifically for China's power sector, and all power generation units with capacity larger than 300 MW ( $\sim 400$ units) were identified as large point sources (LPSs), while other plants were treated as area sources. Similar to China, we also developed a detailed, unit-based inventory for India's power sector. The unit-level information was derived from various series of the Performance Review of Thermal Power Stations (Central Electricity Authority, 2000-2010), and all power generation units with capacity larger than $20 \mathrm{MW}$ ( $\sim 500$ units) were included.

\subsection{Estimation of seasonal variations}

Year-specific monthly temporal distributions for $\mathrm{SO}_{2}, \mathrm{BC}$, and OC emissions from each major sector during 1996-2010 were developed. For the residential sector, we followed the same methodology used in the TRACE-P inventory (Streets et al., 2003), assuming a dependence of stove operation on provincial (or state) monthly mean temperatures, to generate monthly emissions. For the other sectors, monthly temporal distributions were determined from monthly activity data of power generation, industrial GDP (or industrial production index), sulfuric acid and coke production, volume of passenger and freight transported by ship, railway, and aviation, etc. (Reserve Bank of India, 2010; Central Statistical Organization, 2000-2010; NBS, 1997-2010b, c). The monthly emissions of open biomass burning from forest and savanna were obtained directly from GFED v3.1 (van der Werf et al., 2010), and those from agricultural waste burning were determined based on the work of Wang and Zhang (2008) for China and Venkataraman et al. (2006) for India.

\subsection{Data sets of $\mathrm{SO}_{2}$ and $\mathrm{AOD}$}

$\mathrm{SO}_{2}$ and AOD satellite data are used to compare with our emission estimates. The $\mathrm{SO}_{2}$ satellite data are from the Scanning Imaging Absorption Spectrometer for Atmospheric Chartography (SCIAMACHY, aboard the European Space Agency's ENVISAT satellite, launched in March 2002) and the Ozone Monitoring Instrument (OMI, aboard NASA's EOS/Aura satellite, launched in July 2004). Appropriate air-mass factors (AMF) are required to convert the retrieved slant columns of $\mathrm{SO}_{2}$ from both instruments into vertical columns. The value of AMF is dependent on the satellite viewing geometry, the $\mathrm{SO}_{2}$ vertical distribution, the reflectivity (albedo) of the earth's surface, the total column ozone, aerosols, clouds, etc. (Krotkov et al., 2008; Lee et al., 2009). For SCIAMACHY, we used the monthly level-3 product with grid cells of $0.25^{\circ} \times 0.25^{\circ}$ from the Support to Aviation Control Service (SACS, http: //sacs.aeronomie.be/index.php), for which the AMF was pre-calculated with the radiative transfer model LIDORT. For OMI, the planetary boundary layer (PBL) $\mathrm{SO}_{2}$ data in the OMSO2 Level-2G products were used (a fixed global AMF of 0.36 is applied), and they were acquired from NASA's Goddard Earth Sciences Data and Information Services Center (GES-DISC) at http://disc.sci.gsfc.nasa. gov/Aura/data-holdings/OMI/omso2g_v003.shtml. Daily retrievals were first filtered to remove data with large solar zenith angle $\left(>70^{\circ}\right)$, or relatively high radiative cloud fraction $(>0.3)$ and terrain height $(>1.5 \mathrm{~km})$, or anomalous scenes, and then averaged at $0.5^{\circ} \times 0.5^{\circ}$ resolution to reduce the noise (Nickolay Krotkov, personal communication). Annual mean $\mathrm{SO}_{2}$ column amounts were then calculated from the daily data for the years 2005-2010. 
Table 1. Emissions of $\mathrm{SO}_{2}, \mathrm{BC}$, and $\mathrm{OC}$ in China by sector and fuel type (Gg/year).

\begin{tabular}{|c|c|c|c|c|c|c|}
\hline & & 1996 & 2000 & 2004 & 2008 & 2010 \\
\hline \multirow[t]{11}{*}{$\mathrm{SO}_{2}$} & Power plants & 9104 & 9959 & 15655 & 12486 & 6587 \\
\hline & Industry & 11436 & 8559 & 11890 & 16370 & 20388 \\
\hline & Residential & 3212 & 1947 & 2048 & 2365 & 2931 \\
\hline & Transport & 499 & 614 & 865 & 819 & 857 \\
\hline & Coal & 22737 & 19448 & 27697 & 28881 & 27372 \\
\hline & Oil & 709 & 845 & 1363 & 1274 & 1352 \\
\hline & Biofuel & 89 & 87 & 126 & 129 & 127 \\
\hline & Other & 716 & 699 & 1273 & 1756 & 1912 \\
\hline & Forest \& savanna burning & 14 & 23 & 10 & 14 & 14 \\
\hline & Agricultural waste burning & 54 & 51 & 52 & 58 & 58 \\
\hline & Total & 24318 & 21153 & 30520 & 32112 & 30834 \\
\hline \multirow[t]{11}{*}{$\mathrm{BC}$} & Power plants & 12 & 11 & 14 & 19 & 21 \\
\hline & Industry & 527 & 370 & 437 & 510 & 501 \\
\hline & Residential & 790 & 639 & 826 & 888 & 936 \\
\hline & Transport & 92 & 139 & 194 & 259 & 283 \\
\hline & Coal & 849 & 518 & 576 & 636 & 662 \\
\hline & Oil & 141 & 205 & 290 & 396 & 434 \\
\hline & Biofuel & 418 & 417 & 583 & 620 & 619 \\
\hline & Other & 14 & 18 & 21 & 24 & 25 \\
\hline & Forest \& savanna burning & 12 & 19 & 10 & 13 & 12 \\
\hline & Agricultural waste burning & 90 & 86 & 88 & 97 & 97 \\
\hline & Total & 1524 & 1263 & 1569 & 1787 & 1850 \\
\hline \multirow[t]{11}{*}{$\mathrm{OC}$} & Power plants & 12 & 10 & 11 & 10 & 11 \\
\hline & Industry & 520 & 359 & 405 & 446 & 384 \\
\hline & Residential & 2150 & 1893 & 2519 & 2670 & 2790 \\
\hline & Transport & 85 & 152 & 197 & 241 & 260 \\
\hline & Coal & 1120 & 685 & 740 & 821 & 850 \\
\hline & Oil & 102 & 175 & 229 & 284 & 308 \\
\hline & Biofuel & 1528 & 1533 & 2138 & 2234 & 2257 \\
\hline & Other & 17 & 21 & 25 & 28 & 30 \\
\hline & Forest \& savanna burning & 127 & 212 & 88 & 126 & 126 \\
\hline & Agricultural waste burning & 427 & 409 & 419 & 467 & 463 \\
\hline & Total & 3322 & 3035 & 3638 & 3959 & 4033 \\
\hline
\end{tabular}

AOD satellite retrievals are from the Moderate Resolution Imaging Spectroradiometer (MODIS) and Multi-angle Imaging Spectroradiometer (MISR). The MODIS sensors are aboard both the NASA EOS/Terra and EOS/Aqua satellites, which were launched in December 1999 and May 2002, respectively. The MODIS AOD retrieval is based on scene brightness over dark surfaces, using empirical relationships in the spectral variation in surface reflectivity (Remer et al., 2005). The AOD data have discontinuities in some mesh grid points, mainly in middle and high latitudes (i.e., bright land surfaces such as the desert and snow-covered surfaces), which were excluded in the analysis. Besides MODIS, the EOS/Terra satellite also has the MISR instrument on board.
It uses observed differences in the reflective properties of Earth's surface with nine viewing angles to retrieve AOD (Kahn et al., 2005). In this study, the monthly level-3 products of Terra-MODIS (v5.1, $550 \mathrm{~nm}$ ), Aqua-MODIS (v5.1, $550 \mathrm{~nm}$ ), and MISR (v31, $555 \mathrm{~nm}$ ) are used, and they were acquired using the NASA's GES-DISC Interactive Online Visualization and Analysis Infrastructure (Giovanni) (http: //disc.sci.gsfc.nasa.gov/giovanni). Global coverage in the absence of clouds is obtained in one to two days for MODIS and in six to nine days for MISR. Horizontal resolutions are $1^{\circ} \times 1^{\circ}$ and $0.5^{\circ} \times 0.5^{\circ}$ for MODIS and MISR, respectively.

For the purpose of identifying the months in which anthropogenic emissions have the greatest impact on AOD, and 
Table 2. Emissions of $\mathrm{SO}_{2}, \mathrm{BC}$, and $\mathrm{OC}$ in India by sector and fuel type (Gg/year).

\begin{tabular}{|c|c|c|c|c|c|c|}
\hline & & 1996 & 2000 & 2004 & 2008 & 2010 \\
\hline \multirow[t]{11}{*}{$\mathrm{SO}_{2}$} & Power plants & 2550 & 3251 & 3791 & 4708 & 5236 \\
\hline & Industry & 1945 & 1973 & 2102 & 2544 & 2784 \\
\hline & Residential & 374 & 321 & 350 & 543 & 583 \\
\hline & Transport & 263 & 225 & 207 & 192 & 144 \\
\hline & Coal & 3375 & 3779 & 4559 & 6019 & 6730 \\
\hline & Oil & 1533 & 1732 & 1593 & 1638 & 1661 \\
\hline & Biofuel & 87 & 84 & 87 & 99 & 99 \\
\hline & Other & 138 & 175 & 210 & 232 & 257 \\
\hline & Forest \& savanna burning & 17 & 15 & 17 & 14 & 17 \\
\hline & Agricultural waste burning & 36 & 33 & 36 & 42 & 44 \\
\hline & Total & 5185 & 5819 & 6502 & 8044 & 8807 \\
\hline \multirow[t]{11}{*}{$\mathrm{BC}$} & Power plants & 3 & 4 & 4 & 5 & 5 \\
\hline & Industry & 155 & 168 & 198 & 217 & 227 \\
\hline & Residential & 402 & 421 & 481 & 563 & 579 \\
\hline & Transport & 80 & 88 & 88 & 107 & 111 \\
\hline & Coal & 177 & 172 & 209 & 276 & 295 \\
\hline & Oil & 117 & 126 & 124 & 153 & 159 \\
\hline & Biofuel & 338 & 373 & 426 & 449 & 454 \\
\hline & Other & 8 & 10 & 12 & 14 & 15 \\
\hline & Forest \& savanna burning & 19 & 17 & 19 & 16 & 19 \\
\hline & Agricultural waste burning & 60 & 56 & 59 & 71 & 74 \\
\hline & Total & 718 & 753 & 850 & 979 & 1015 \\
\hline \multirow[t]{11}{*}{$\mathrm{OC}$} & Power plants & 6 & 8 & 10 & 12 & 14 \\
\hline & Industry & 155 & 166 & 195 & 208 & 214 \\
\hline & Residential & 1379 & 1476 & 1725 & 1899 & 1946 \\
\hline & Transport & 52 & 61 & 56 & 58 & 54 \\
\hline & Coal & 203 & 186 & 226 & 322 & 346 \\
\hline & Oil & 67 & 76 & 70 & 75 & 72 \\
\hline & Biofuel & 1313 & 1438 & 1676 & 1763 & 1792 \\
\hline & Other & 9 & 11 & 14 & 17 & 17 \\
\hline & Forest \& savanna burning & 157 & 142 & 158 & 133 & 157 \\
\hline & Agricultural waste burning & 287 & 269 & 285 & 340 & 354 \\
\hline & Total & 2035 & 2122 & 2429 & 2651 & 2739 \\
\hline
\end{tabular}

obtaining the conversion factors between AOD and emission mass (see Sect. 4.1 in detail), we use results from the GOCART model updated to version c3.1 simulation for 20002007 (Chin et al., 2009) (available on Giovanni). The GOCART model simulates physical and chemical processes of major tropospheric aerosol components, including sulfate, dust, BC, OC, and sea salt, as well as the precursor gaseous species of $\mathrm{SO}_{2}$ and dimethylsulfide (DMS). It uses the assimilated meteorological fields of the Goddard Earth Observing System Data Assimilation System (GEOS DAS) version 4, with a spatial resolution of $1^{\circ}$ latitude by $1.25^{\circ}$ longitude, and 30 vertical sigma layers. The annual anthropogenic emissions of $\mathrm{SO}_{2}, \mathrm{BC}$, and $\mathrm{OC}$ are based on our previous work
(Bond et al., 2004; Streets et al., 2006, 2009), and timevarying emissions from aircraft and ships, biomass burning, biogenic, oceanic and volcanic sources, wind-blown dust, sea salt, and so on are also included. AOD in the model is determined from the dry mass concentrations and mass extinction efficiencies which are calculated from Mie theory on the basis of size distributions, refractive indices, and hygroscopic properties of individual aerosol types. 

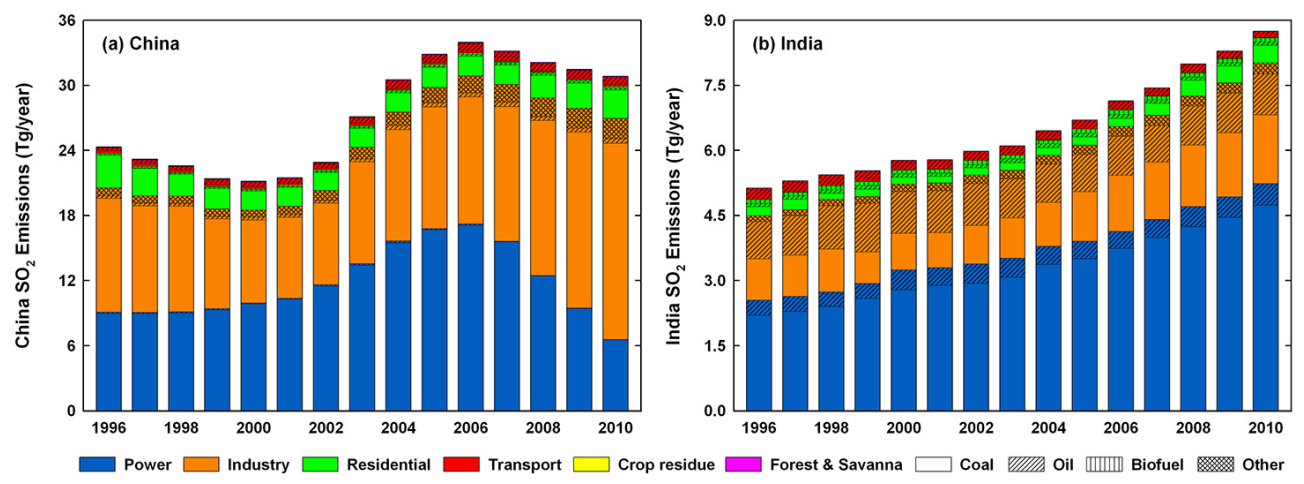

Fig. 2. $\mathrm{SO}_{2}$ emissions by sector and fuel type in (a) China and (b) India during 1996-2010.
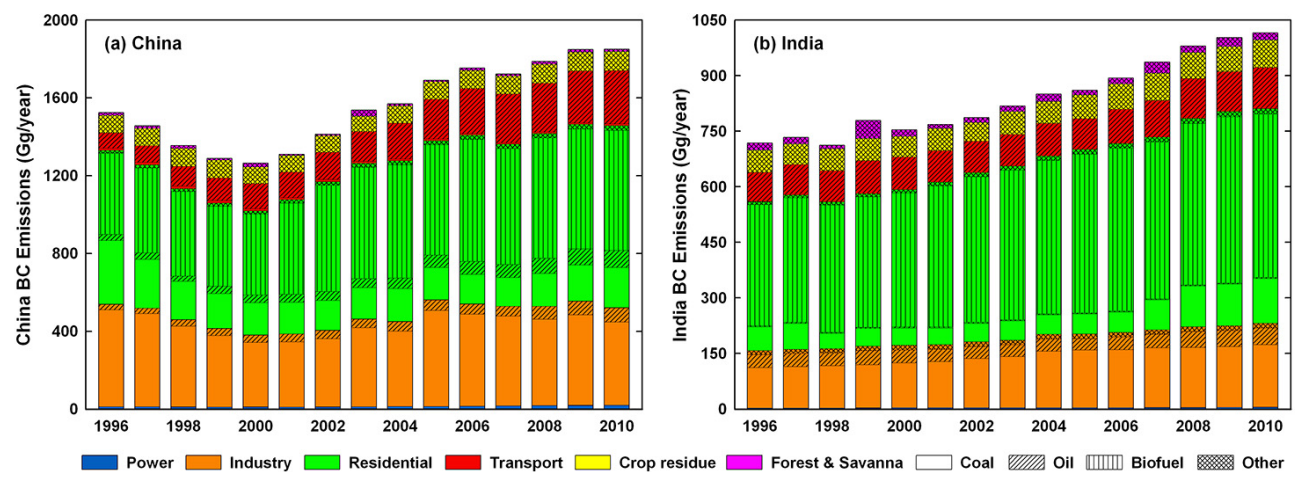

Fig. 3. BC emissions by sector and fuel type in (a) China and (b) India during 1996-2010.

\section{Emissions of $\mathrm{SO}_{2}, \mathrm{BC}$, and $\mathrm{OC}$ from China and India during 1996-2010}

\subsection{Emissions overview}

Tables 1 and 2 summarize $\mathrm{SO}_{2}, \mathrm{BC}$, and $\mathrm{OC}$ emissions by major emitting sector and fuel type in China and India, respectively, during 1996-2010. The net emission factors are shown in Tables S3 and S4 in the Supplement.

\subsection{1 $\mathrm{SO}_{2}$}

Figure 2a shows the annual trend of $\mathrm{SO}_{2}$ emissions and its distribution among sectors and fuel types in China. Generally, the trend can be divided into three distinct time periods. During 1996-2000, $\mathrm{SO}_{2}$ emissions decreased by $13 \%$ from $24.3 \mathrm{Tg}$ to $21.2 \mathrm{Tg}$. This is consistent with the estimates of previous work (Ohara et al., 2007; Smith et al., 2011; Streets et al., 2006, 2008), and the decline is attributed to the combination of a slowdown in economic growth caused by the Asian economic crisis, the fundamental restructuring of the Chinese industrial economy, a decline in coal use in the residential and industrial sectors, and a reduction in the average sulfur content of coal burned (Ohara et al., 2007; Streets et al., 2003). After 2000, $\mathrm{SO}_{2}$ emissions in China increased dramatically by $61 \%$ from $21.2 \mathrm{Tg}$ in 2000 to $34.0 \mathrm{Tg}$ in
2006, with an annual growth rate (AGR) of $8.2 \%$. This growth rate is slightly higher than our previous estimate of $7.3 \%$ (Lu et al., 2010), which was calculated from official Chinese energy statistics, but is still in good agreement with values reported in other bottom-up inventories (6.3\%-9.9\%) (Klimont et al., 2009; Ohara et al., 2007; Smith et al., 2011; Zhang et al., 2009b) and derived from satellite constraints (6.2\%-9.6\%) (van Donkelaar et al., 2008). The dramatic change during this period was driven by the rapid increase of energy consumption (87\% growth, Fig. 1a) due to the economic boom (99\% growth in GDP). Although GDP and energy consumption in China were still increasing after 2006, national $\mathrm{SO}_{2}$ emissions began to decrease, due to the application of FGD technology and the phase-out of small, highemitting power generation units (Lu et al., 2010). During 2000-2010, the average FGD penetration rate in China increased from $1 \%$ to $78 \%$, and the net emission factor of coal-fired power plants decreased by $76 \%$ correspondingly (Table S3 in the Supplement). By the end of 2010, FGD penetration of power plants had risen to $83 \%$, which is estimated to eliminate about $19.4 \mathrm{Tg} \mathrm{SO}_{2}$ in that year. In terms of fuel-type and sectoral contribution, coal combustion was the single largest contributor ( $89 \%-93 \%)$. Emissions from the power sector increased from $37 \%$ in 1996 to $51 \%$ in 2004, and later decreased to $21 \%$ in 2010 . The contribution of 
industry decreased from $47 \%$ in 1996 to $38 \%$ in 2002, but increased to $66 \%$ in 2010 . The share of the residential sector slightly varied between $6 \%$ and $13 \%$. The ongoing tension between two forces - economic development and environmental protection - causes the emission trends to be decidedly non-linear, as the government imposes new measures to address one aspect of air pollution or another, and it is important to reflect these significant changes from year to year in emissions and impacts analysis.

The temporal evolution of $\mathrm{SO}_{2}$ emissions from India and its sectoral and fuel-type distribution between 1996 and 2010 is shown in Fig. 2b. In contrast to the situation in China, anthropogenic $\mathrm{SO}_{2}$ in India shows a continuously increasing trend, which reflects rapid economic and social development driven by growing fossil-fuel use and relatively lax emission controls. The national emissions increased by $70 \%$ from 5.2 Tg in 1996 to $8.8 \mathrm{Tg}$ in 2010 with an AGR of $3.9 \%$. Power plants are the main sources of $\mathrm{SO}_{2}$ (contributing $49 \%$ in 1996 and $59 \%$ in 2010 to the total emissions), followed by industry $(\sim 34 \%)$, residential $(\sim 6 \%)$, and transportation $(\sim 3 \%)$. Compared to a $35 \%$ increase in emissions in other sectors, $\mathrm{SO}_{2}$ emission from power plants increased by $105 \%$, from $2.6 \mathrm{Tg}$ in 1996 to $5.2 \mathrm{Tg}$ in 2010, which can be viewed in the context of a $117 \%$ increase of total thermal-based electricity generation during the same period. Although the contribution of emissions from coal combustion $(\sim 69 \%)$ is smaller than that of China ( $>89 \%$ ), it dominates the growth of national emission. During 1996-2010, $\mathrm{SO}_{2}$ emissions from coal combustion increased by $3.4 \mathrm{Tg}$, accounting for $93 \%$ of the national growth.

\subsubsection{BC}

Figure 3 displays $\mathrm{BC}$ emissions by sector and by fuel type in China and India. Although both $\mathrm{SO}_{2}$ and $\mathrm{BC}$ are mainly from the process of fuel combustion, and the trends between $\mathrm{SO}_{2}$ and $\mathrm{BC}$ emissions are similar to some extent in China and India, the emission distributions among sectors and fuel types are quite different. First, BC is produced mostly from incomplete combustion in small, low-temperature facilities and not power plants or large industrial facilities, whereas $\mathrm{SO}_{2}$ emissions are closely related to the total coal and oil use. Second, a significant amount of BC is produced from biofuel combustion and open biomass burning, whereas both of these generate little $\mathrm{SO}_{2}$.

In China, the trend of $\mathrm{BC}$ emissions is controlled by the balance between decreasing net emission factors for major sources and increasing activity rates. To improve air quality, the Chinese government has issued a series of emission standards for PM emitting sources during 1996-2010, and a large number of emission reduction measures have been implemented. These include: replacing cyclones and wet scrubbers on power and industrial boilers with electrostatic precipitators and fabric filters; increasing the market share of boilers with large capacity; converting residential coal use from raw coal to briquettes, and introducing cleaner fuels like LPG and electricity; phasing out beehive brick kilns and indigenous coke production facilities; implementing vehicle emission standards from Euro I to Euro IV, etc. (Chen et al., 2009; Lei et al., 2011; Zhang et al., 2009b). As a result, these measures caused dramatic changes in the technology distribution as well as the emission factors in the relevant sectors. For example, the mean BC emission factors of coal consumed in the industrial and residential sector decreased by $64 \%$ and $34 \%$, respectively, during 1996-2010 (Table S3 in the Supplement). The decrease of emission factors for major BC sources (except for biofuel combustion), along with the decrease of industrial and residential coal consumption, is the main reason for a $17 \% \mathrm{BC}$ emission decline in China during 1996-2000 (Fig. 3a). Although the emission factors for major BC sources were still decreasing after 2000, BC emissions in China increased by $46 \%$ from $1.26 \mathrm{Tg}$ in 2000 to $1.85 \mathrm{Tg}$ in 2010 . This was driven by rapidly increasing energy consumption (144\% growth, Fig. 1a), industrial production (e.g., $292 \%$ growth in coke production), and vehicle population (366\% growth). The dramatic increase of activity rates counteracts the effect of technology improvements, and makes the $\mathrm{BC}$ emissions continuously grow. Examining the sectoral distributions, the residential sector is the main source of BC $(51 \% \pm 3 \%)$. The contribution of the industry sector decreased from $35 \%$ in 1996 to $27 \%$ in 2010, whereas that of transportation increased from $6 \%$ to $15 \%$.

Although there were some PM reduction measures in India during 1996-2010 (e.g., replacing traditional cookstoves with improved cookstoves, implementing new emission standards for vehicles, etc.), the progress was not as fast as in China. As shown in Table S4 in the Supplement, the mean emission factors of major BC sources only have small changes over time. Therefore, the trend of $\mathrm{BC}$ emissions in India is governed by the trend of energy consumption. Figure $3 \mathrm{~b}$ shows that $\mathrm{BC}$ emissions from India increased steadily from $0.72 \mathrm{Tg}$ in 1996 to $1.02 \mathrm{Tg}$ in 2010, with an AGR of $2.5 \%$. Biofuel combustion was the dominant contributor in India $(45 \%-52 \%)$, followed by coal $(22 \%-29 \%)$ and oil $(14 \%-17 \%)$. The distribution of $\mathrm{BC}$ emissions among different sectors was relatively stable during 1996-2010, at about $57 \%, 22 \%, 11 \%, 8 \%$, and $2 \%$ for residential, industry, transportation, agricultural waste burning, and forest and savanna burning, respectively.

\subsubsection{OC}

Similar to the BC trend for China, the anthropogenic OC emissions (i.e., excluding forest and savanna burning) decreased from $3.20 \mathrm{Tg}$ in 1996 to $2.82 \mathrm{Tg}$ in 2000 , but then increased to $3.91 \mathrm{Tg}$ in 2010 (Fig. 4a). The residential sector (69\%), especially for biofuel combustion (56\%), is the dominant contributor of anthropogenic OC emissions in China. With the rapid increase of vehicle population and continuous decrease of emission factor in industrial coal use, the share 

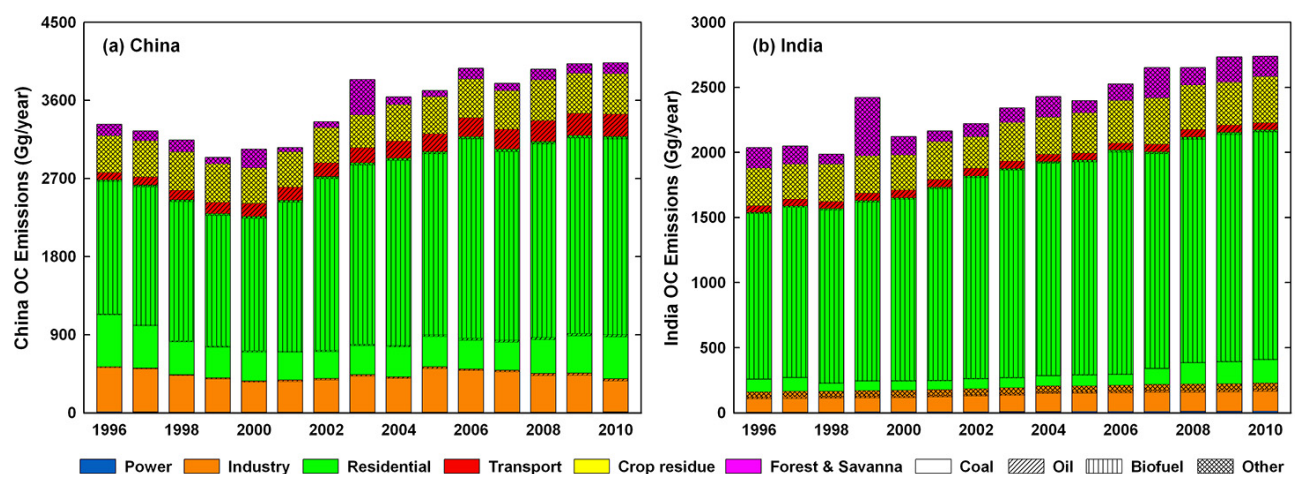

Fig. 4. OC emissions by sector and fuel type in (a) China and (b) India during 1996-2010.

of transportation increased from $3 \%$ in 1996 to $7 \%$ in 2010, and that of industry decreased from $16 \%$ to $10 \%$. Open biomass burning of agricultural waste is another large source, accounting for about $13 \%$ of the anthropogenic OC emissions. For India, anthropogenic OC increased by $38 \%$ from $1.88 \mathrm{Tg}$ to $2.58 \mathrm{Tg}$ during $1996-2010$ (Fig. $4 \mathrm{~b}$ ). The highest sectoral contributor is from the residential sector $(75 \%$, in which biofuel combustion accounts for $96 \%$ ), followed by agricultural waste burning (14\%), industry ( $8 \%$ ), and transportation (3\%).

We note a significant year-to-year variation in OC emissions from open biomass burning of forest and savanna, which is determined by the extent of fires, and is driven largely by precipitation amounts and soil moisture content. OC emissions from this source type accounted for $2 \%-11 \%$ and $4 \%-18 \%$ of the total emissions in China and India, depending on the year. As shown in Fig. 4, 2003 was a year of extensive open biomass burning in China, while 1999 was such a year for India. This variability is the main cause of the interannual fluctuations in the trend of total OC emissions in China and India.

\subsection{Uncertainties}

Using the Monte Carlo approach, we provide $95 \%$ CIs for all the model outputs. The uncertainty ranges of $\mathrm{SO}_{2}, \mathrm{BC}$, and $\mathrm{OC}$ emissions by major sector and fuel type are shown in Tables S1 and S2 in the Supplement for China and India, respectively. The net emission factor uncertainties by sector and fuel type are listed in Tables S3 and S4 in the Supplement. Since $\mathrm{SO}_{2}$ emission is largely dependent on sulfur contents and activity rates of fossil fuels, it has lower uncertainty than BC and OC emissions which are strongly influenced by combustion condition. The average uncertainties of $\mathrm{SO}_{2}, \mathrm{BC}$, and $\mathrm{OC}$ emissions were estimated to be $-16 \%$ to $17 \%,-43 \%$ to $93 \%$, and $-43 \%$ to $80 \%$ for China, and $-15 \%$ to $16 \%,-41 \%$ to $87 \%$, and $-44 \%$ to $92 \%$ for India. The right subgraphs of Figs. 5 and 6 display the emission distributions of each species in the year 2010, according to Monte Carlo simulations. The distribution of $\mathrm{SO}_{2}$ is ap- proximately symmetric since most of the relevant parameters were assumed to have normal or uniform distributions. BC and OC distributions are asymmetric, reflecting our lognormal treatment of emission factors and biofuel consumption. Table 3 shows the average contribution of each sector to total uncertainties during 1996-2010. Power plants and industry contribute more than $83 \%$ of the $\mathrm{SO}_{2}$ emission uncertainty in both China and India. The residential sector is the single largest contributor to uncertainty of carbonaceous aerosol emissions ( $>60 \%$ for BC and $>67 \%$ for OC), followed by industry, open biomass burning, transportation, and power plants. Examining the interannual variation of the uncertainty for all three species in both countries, $95 \%$ CIs have no obvious change except for BC emissions in China (Tables S1 and S2 in the Supplement). The significant decrease of China's BC uncertainty over time can be explained by the decreasing share of residential and industry emissions, which are highly uncertain.

We also conducted sensitivity analysis of the outputs. As shown in Fig. 7, the results are expressed as the contribution of each parameter in the model to the total variance of emission estimates. In this study, more than 600 input parameters are included in the Monte Carlo framework. We therefore aggregated them into several major parameters or fuel/usage combinations. For example, the combination "oil" in Fig. 7a and $b$ includes the contributions of sulfur contents and fuel use of all kinds of oils; the combination "Wood/RE" in Fig. 7c-f includes the contributions of technology divisions, fuel use, and all emission factor determinants of fuelwood combustion in the residential sector.

For $\mathrm{SO}_{2}$ emissions in China, hard-coal related parameters contributed to more than $96 \%$ of the variances before 2005 (Fig. 7a). The proportions of sulfur content, fuel use, and sulfur retention in ash of hard coal were $61 \%, 27 \%$, and $10 \%$, respectively. After $2005, \mathrm{SO}_{2}$ emissions were sensitive to the FGD removal efficiency, the shares of which in the variances were in the range of $1 \%$ to $16 \%$, depending on the year. As we mentioned previously, FGD devices were widely installed during China's 11 th Five-Year Plan period (2006-2010). However, the actual operation of FGD 

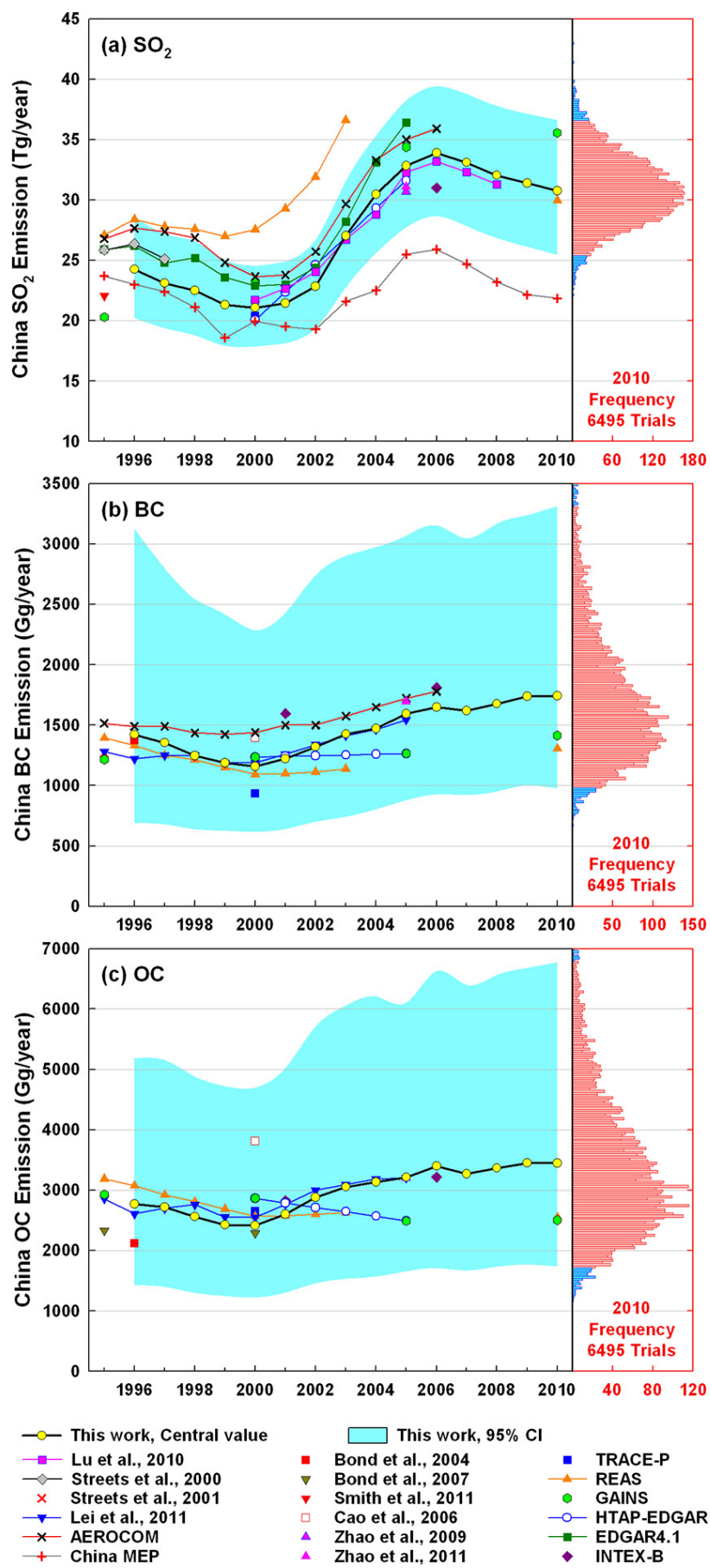

Fig. 5. Comparison of emission estimates (excluding emissions from open biomass burning) for China: (a) $\mathrm{SO}_{2}$, (b) $\mathrm{BC}$, and (c) OC. The right subgraphs present the distributions of estimated emissions in 2010. The blue bars are beyond the $95 \%$ CIs.

equipment is unknown. It was reported that China's official data overestimated the actual performance of $\mathrm{SO}_{2}$ scrubbers before 2007 (Xu et al., 2009; Xu, 2011). For example, official data announced that $73.2 \%$ of $\mathrm{SO}_{2}$ was removed
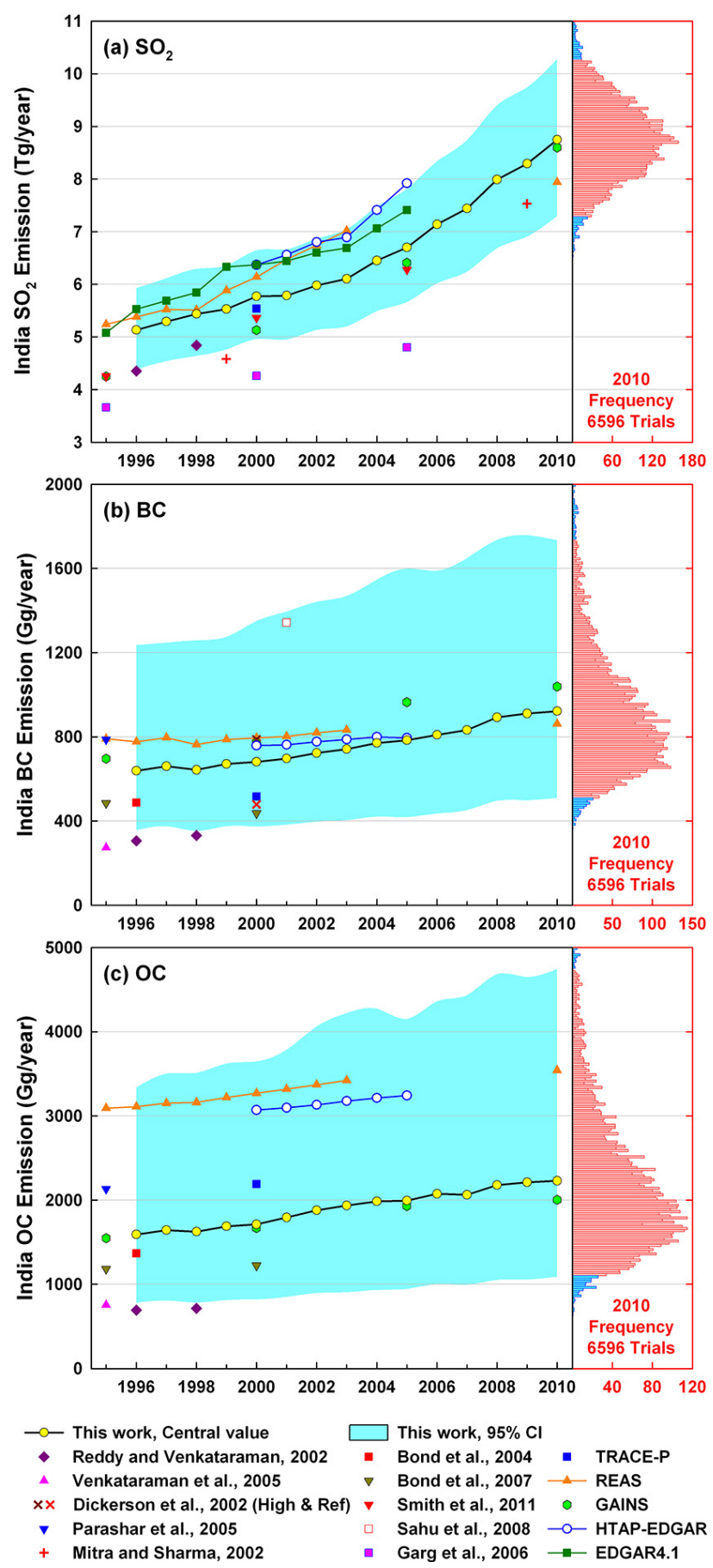

Fig. 6. Comparison of emission estimates (excluding emissions from open biomass burning) for India: (a) $\mathrm{SO}_{2}$, (b) BC, and (c) OC. The right subgraphs present the distributions of estimated emissions in 2010. The blue bars are beyond the $95 \%$ CIs.

from coal-fired power plants that had FGD in 2007 (MEP, 2009), whereas this rate was found to be only $64.1 \%$ in the coastal province of Jiangsu, which has a relatively good track record on environmental protection (Xu et al., 2009). Due to 

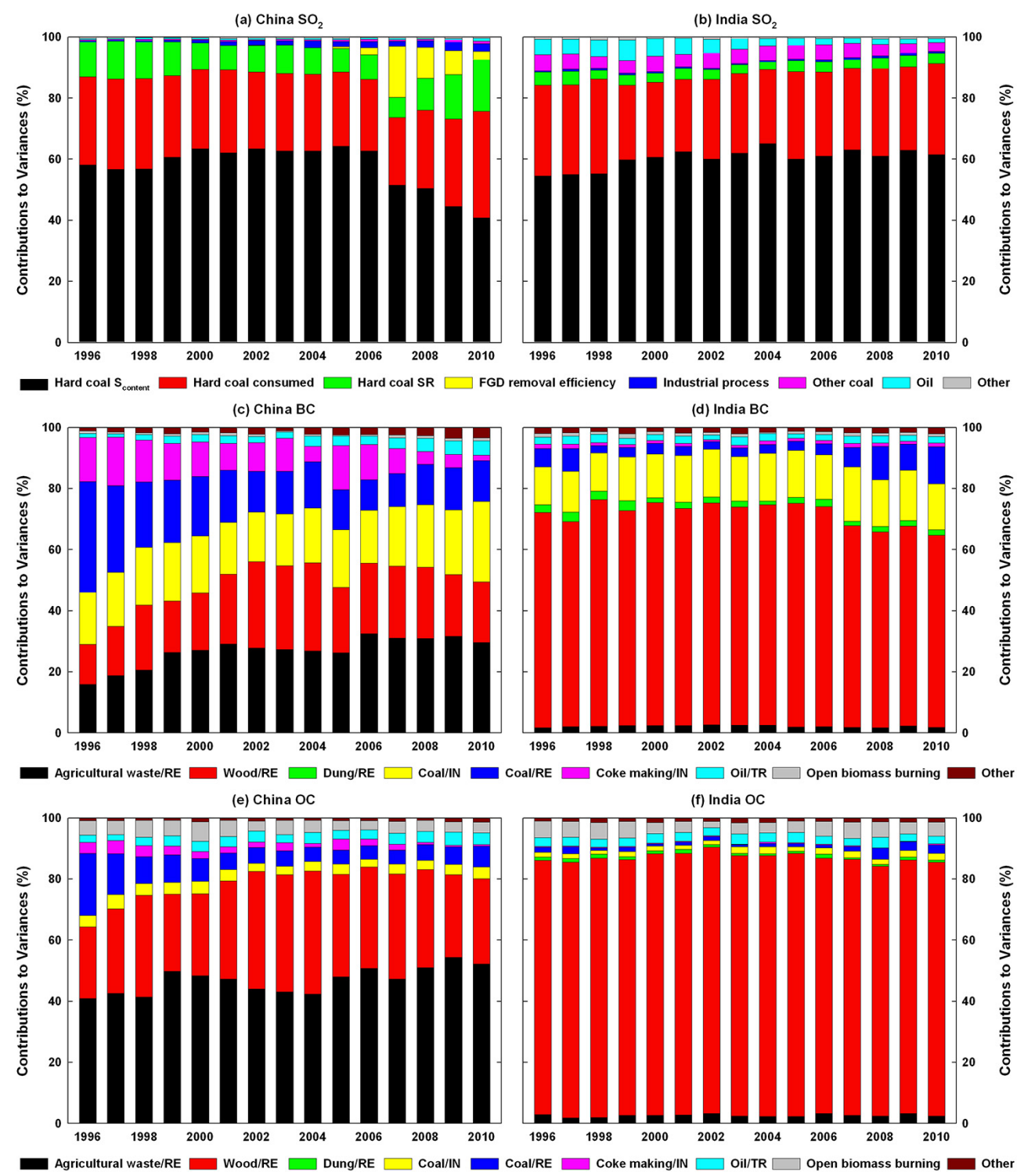

Fig. 7. The contributions of major parameters or fuel/usage combinations to variance in $\mathrm{SO}_{2}(\mathbf{a}, \mathbf{b}), \mathrm{BC}(\mathbf{c}, \mathbf{d})$, and $\mathrm{OC}(\mathbf{e}, \mathbf{f})$ emissions from China (a, c, e) and India (b, d, f) during 1996-2010. IN, RE, and TR represent industry, residential, and transportation sector, respectively.

Table 3. Average contribution of each sector to total uncertainties during 1996-2010 (unit: \%).

\begin{tabular}{lllllllll}
\hline & \multicolumn{3}{c}{ China } & & \multicolumn{3}{c}{ India } \\
\cline { 2 - 3 } \cline { 8 - 9 } & $\mathrm{SO}_{2}$ & $\mathrm{BC}$ & $\mathrm{OC}$ & & $\mathrm{SO}_{2}$ & $\mathrm{BC}$ & $\mathrm{OC}$ \\
\hline Power plants & 37 & 2 & 0 & & 46 & 1 & 1 \\
Industry & 47 & 29 & 14 & & 37 & 23 & 8 \\
Residential & 13 & 60 & 67 & & 10 & 65 & 74 \\
Transport & 2 & 6 & 6 & & 3 & 6 & 1 \\
Forest \& savanna burning & 0 & 1 & 2 & & 1 & 2 & 4 \\
Agricultural waste burning & 1 & 3 & 11 & & 3 & 5 & 12 \\
\hline
\end{tabular}

the sharply expanded FGD installation and low FGD operation, the parameter "FGD removal efficiency" played an increasingly important role in the uncertainty of national emissions during 2005-2007 (Fig. 7a). However, the situation has changed since 2007. To motivate the use of FGD equipment, the Chinese government has taken several measures since 2007, including the installation of continuous monitoring systems in power plants with FGD, the implementation of a premium/penalty scheme of electricity price that varies with the FGD's operation, and severe penalties for the nonoperation of FGD (Xu, 2011). These new policy incentives were reported to be effective. For example, also in Jiangsu province, FGD devices were found to be operating with $\mathrm{SO}_{2}$ removal efficiencies of over $90 \%$ for more than $90 \%$ of the 
time after July 2007 (Xu et al., 2009). Most FGD devices in China operate properly in 2009 based on a series of field interviews conducted by $\mathrm{Xu}$ (2011). Therefore, the importance of FGD removal efficiency to the emission uncertainty is reducing after 2007 (Fig. 7a). Similar to China, hard-coal related parameters are also the largest contributors to the $\mathrm{SO}_{2}$ emission variances in India ( $>89 \%$, Fig. $7 b$ ), and their contributions are continuously increasing over time due to the increasing share of hard coal in the Indian energy structure (Fig. 1b).

The contributions of major fuel/usage combinations to variances of carbonaceous aerosol emissions in China and India are shown in Fig. 7c-f. For BC emissions in China, combustion of residential agricultural waste, residential fuelwood, residential coal, industrial coal, and coke-making process are the largest contributors, together comprising $91 \%-$ $97 \%$ of the variances (Fig. 7c). The shares of fuel/usage combinations are changing over time, reflecting the changes of technology divisions, emission characteristics, and activity rates. For example, we estimate the shares of the mechanized and the indigenous (i.e., traditional) coking facilities by using the coke productions of these two manufacturing technologies, which are reported annually in the China Industry Economy Statistical Yearbook (NBS, 1997-2010a). Based on the official statistics, the share of indigenous coking facilities, the emission characteristics of which are highly uncertain, decreased from $50 \%$ to $0 \%$ during 1996-2010. As a result, the contribution of the coke-making process to the variance has decreased from about $15 \%$ in 1996 to $2 \%$ in 2010. Similarly, the contribution of residential coal combustion to variance decreased from $36 \%$ to $13 \%$, and the reason is mainly attributed to the increasing proportion of briquettes used in residential stoves. Different from BC, OC emissions in China are much more sensitive to residential biofuel combustion (Fig. 7e), which accounts for $64 \%-84 \%$ of the variances. The second largest variance is due to residential coal combustion, accounting for $4 \%-20 \%$ of the variances, depending on the year. Due to the relatively lax application of PM emission controls in India, the contributions of major fuel/usage combinations to variances of carbonaceous aerosol emissions were relatively stable during 1996-2010 (Fig. 7d and f). For BC emissions in India, the largest variance is due to the residential fuelwood combustion $(\sim 70 \%)$, followed by coal combustion in the industrial $(\sim 15 \%)$ and residential $(\sim 5 \%)$ sectors. Residential fuelwood combustion accounts for an even higher rate for Indian OC emission variances $(>83 \%)$. It should be noted that the transportation sector is not a big contributor to variance of either species in China and India $(<3 \%)$. This is different from the situation in regions like North America and Europe (Bond et al., 2004), because carbonaceous aerosol emissions in China and India are mainly from residential biofuel and coal combustion, which have higher uncertainties. For both countries, open biomass burning only contributes $1 \%$ and $4 \%$ of the $\mathrm{BC}$ and $\mathrm{OC}$ emission variances, respectively. This is much lower than the fractions estimated by Bond et al. (2004). The reason is mainly due to the improved methodology in estimating the open burning of agricultural waste and the use of GFEDv3.1 datasets, the uncertainty of which is relatively well quantified.

One benefit of Fig. 7 is that it can point out areas in which additional research could help to reduce uncertainties. For $\mathrm{SO}_{2}$ emissions, more information on sulfur contents of coals and precise coal consumption data are essential to get reliable emission estimates. More field measurements of PM emission characteristics in residential biofuel combustion, residential/industrial coal combustion, and coke making will be critical to improve the carbonaceous aerosol emission estimates in the future.

\subsection{Comparison with previous studies}

\subsubsection{Bottom-up inventories}

Figures 5 and 6 compare the emission estimated in this study (excluding emissions from open biomass burning) to other bottom-up inventories, including regional and global inventories, such as GAINS (Klimont et al., 2009), REAS (Ohara et al., 2007), TRACE-P (Streets et al., 2003), INTEXB (Zhang et al., 2009b), HTAP-EDGAR (http://edgar.jrc.it/ eolo/), EDGAR4.1 (JRC/PBL, 2010), AEROCOM (http:// dataipsl.ipsl.jussieu.fr/AEROCOM/emissions.html), Bond et al. (2004, 2007), and Smith (2011); and country-specific emission estimates, such as Lu et al. (2010), Streets et al. (2000, 2001), Lei et al. (2011), Cao et al. (2006), and Zhao et al. $(2009,2011)$ for China, and Reddy and Venkataraman (2002a, b), Venkataraman et al. (2005), Dickerson et al. (2002), Parashar et al. (2005), Mitra and Sharma (2002), Sahu et al. (2008), and Garg et al. (2006) for India. Some of these other estimates are trends, and some are single-year estimates.

As shown in Figs. 5a and 6a, most previous estimates of $\mathrm{SO}_{2}$ emissions from China and India are within the $95 \%$ CIs of the current study, except for China's $\mathrm{SO}_{2}$ emission estimated by the REAS (Ohara et al., 2007) and reported by the China MEP (MEP, 2011), and India's emission estimated by Garg et al. (2006). The discrepancies between different studies are caused by a combined effect of the different amounts and distribution of fuel consumption between sectors and the implied emission factor assumptions (Klimont et al., 2009). China's $\mathrm{SO}_{2}$ emissions in the REAS inventory have been found to be too high by a number of researchers (Aikawa et al., 2010; Klimont et al., 2009; Lu et al., 2010; Smith et al., 2011; Zhang et al., 2009b; Zhao et al., 2011), especially for the period after 2000. After examining the emissions carefully, we attribute the discrepancies mainly to the high emission factors chosen in the REAS inventory. For example, the emission factor for industrial coal combustion in the REAS inventory is $934.2 \mathrm{~g} \mathrm{GJ}^{-1}$ in 2000 , which is $70 \%$ higher than our value $\left(549.2 \mathrm{~g} \mathrm{GJ}^{-1}\right)$ and outside our uncertainty range 
(449.9-660.1 $\mathrm{g} \mathrm{GJ}^{-1}$ ) (Table S3 in the Supplement). Due to this factor alone, $\mathrm{SO}_{2}$ emissions in China in REAS are overestimated by $4.2 \mathrm{Tg}$ in 2000. Although efficiencies of $\mathrm{SO}_{2}$ removal by power plants were considered in three REAS scenarios in China, the main reason for the consistency between the REAS and our estimate in 2010 is the seriously underestimated fuel consumption in China. The fuel consumption was projected to be $57.9 \mathrm{EJ}$ in the REAS reference scenario of 2010, which is $45 \%$ lower than our data (105.6 EJ, Fig. 1). Comparing with REAS, China's fuel consumption in 2010 in the GAINS model (97.1 EJ) is much closer to the actual data. However, the net emission factor of power plants for coal in the GAINS model $\left(677 \mathrm{~g} \mathrm{GJ}^{-1}\right.$ and $440 \mathrm{~g} \mathrm{GJ}^{-1}$ for old and new power plants, respectively) is much higher than the current work (mean value of $204 \mathrm{~g} \mathrm{GJ}^{-1}$, see Table S3 in the Supplement and Sect. 3.1.1). For this reason, the GAINS's estimation in 2010 is higher than this study. Our estimates follow the trend of values reported by the China MEP (MEP, 2011) $(\mathrm{R}=0.83)$, but are significantly higher, which may be caused by the omission of $\mathrm{SO}_{2}$ emissions from rural industries and biofuels in the China MEP inventory (Streets et al., 2003; Zhang et al., 2009b). For India, all of the estimates show an increasing $\mathrm{SO}_{2}$ emission trend during 19962010 (Fig. 6a). The AGR of our estimates is $3.9 \%$, which is in line with AGRs of $3.5 \%-5.1 \%$ estimated by other researchers during this period. The Garg et al. (2006) values are below the lower bounds of the $95 \%$ CIs calculated in this study. This is mainly due to the lower coal consumption ( $25 \%$ lower than this study) used in their calculation.

In general, the agreement among estimates of $\mathrm{BC}$ emissions for China is reasonably good (Fig. 5b), though these studies rely to a greater or lesser extent on the same original emission factors presented by Streets et al. (2001) and Bond et al. (2004), which, however, have a much larger uncertainty. For India, the data are more scattered (Fig. 6b), mainly due to the widely varying emission factors for residential biofuel combustion that were applied in the different studies. For example, the $\mathrm{BC}$ emission factors of residential biofuel are about $1.0-1.3 \mathrm{~g} \mathrm{~kg}^{-1}$ in GAINS, REAS, TRACE-P, and Parashar et al. (2005), which are at least twice the values used in Bond et al. (2004, 2007), Reddy and Venkataraman (2002b), and Venkataraman et al. (2005) (around $0.5 \mathrm{~g} \mathrm{~kg}^{-1}$ ). In this work, new emission factors for biofuel combustion obtained from field tests have been incorporated (Habib et al., 2008; Parashar et al., 2005; Venkataraman et al., 2005). However, it remains the situation that much of the underlying analytical approach relies on emission factors extracted from PM measurements in developed countries that may or may not be reflective of the true nature of Chinese and/or India emitters. Even when emission factors have been measured in field tests in developing countries, there is a surprisingly high uncertainty, reflective of the fact that the conditions of the stove, air flow, fuel, and combustion conditions - which vary from household to household - dictate the nature of the particles that are generated. The aggregate amount of fuel burned in households must also inevitably be uncertain. Besides the lower BC emission factors of residential biofuel used in Venkataraman et al. (2005) and Reddy and Venkataraman (2002a, b), the fact that emissions estimated in these two studies are slightly below the lower bounds of $95 \%$ CIs of this work is also attributed to the omission of sources like residential coal combustion and/or biofuel consumption for heating. Although Sahu et al. (2008)'s estimation $(1344 \mathrm{Gg}$ ) for 2001 lies within the uncertainty range estimated here, they used extremely high emission factors for fossil fuels, which are no longer used by the community.

Figures $5 \mathrm{c}$ and $6 \mathrm{c}$ compare the $\mathrm{OC}$ emissions from China and India estimated in this study to other work. For China, the agreement among different estimates is quite good, although the emission factors are highly uncertain. OC emission estimates are generally in the range of $2.0-3.5 \mathrm{Tg} \mathrm{yr}^{-1}$, with the exception of the point estimate of $3.8 \mathrm{Tg}$ for 2000 by Cao et al. (2006), whose industrial emission value (1.12 Tg) was much higher than other studies (around $0.03 \mathrm{Tg}$ ). The agreement for OC emissions in India is even worse than for BC. The poor agreement is attributed to the enhanced role of biofuel/biomass burning and the difficulties in obtaining good emission factors and estimating reliable activity levels for these sources. The laboratory-test results of Venkataraman et al. (2005) and Habib et al. (2008) indicate that OC emission factors of fuelwood are about $0.4 \mathrm{~g} \mathrm{~kg}^{-1}$ at low burn rates, whereas they rise to $2.7 \mathrm{~g} \mathrm{~kg}^{-1}$ at high burn rates. Their results also show that the OC emission factor varies in the range of $0.6-4.7 \mathrm{~g} \mathrm{~kg}^{-1}$ between different types of agricultural residue. For dung cake, their measurements give an OC emission factor of about $2.4 \mathrm{~g} \mathrm{~kg}^{-1}$; however, Parashar et al. (2005) found it could be as high as $12.6 \mathrm{~g} \mathrm{~kg}^{-1}$ under smoldering conditions during its use as a source of energy in rural areas of India. OC emission factors of biofuel used in other studies in Fig. $6 \mathrm{c}$ are $3.45 \mathrm{~g} \mathrm{~kg}^{-1}$ for GAINS, $5.0 \mathrm{~g} \mathrm{~kg}^{-1}$ for TRACE-P, and $6.28 \mathrm{~g} \mathrm{~kg}^{-1}$ for REAS. The large range of emission factors brings high uncertainty to the OC estimates, especially for India, where biofuel combustion is dominant.

\subsubsection{Uncertainty range}

We have compared our uncertainty ranges with those reported in other studies. Our estimated uncertainty ranges of $\mathrm{SO}_{2}$ emissions (about $\pm 16 \%$ ) are close to the results of TRACE-P $( \pm 13 \%)$, INTEX-B $( \pm 12 \%)$, and Zhao et al. (2011) $( \pm 14 \%)$ for China, but lower than TRACE-P for India $( \pm 26 \%)$ and Smith et al. (2011) for both China $( \pm 29 \%)$ and India $( \pm 24 \%)$. Estimates of carbonaceous aerosol emissions in this work are significantly improved. The average uncertainty ranges of BC $(-43 \%-93 \%)$ and OC $(-43 \%-80 \%)$ in China are much lower than the results in TRACE-P $(-83 \%-584 \%$ for BC and $-83 \%-595 \%$ for OC), INTEX-B $(-68 \%-308 \%$ for BC and $-72 \%-$ $358 \%$ for OC), Lei et al. (2011) ( $-65 \%-287 \%$ for BC and 

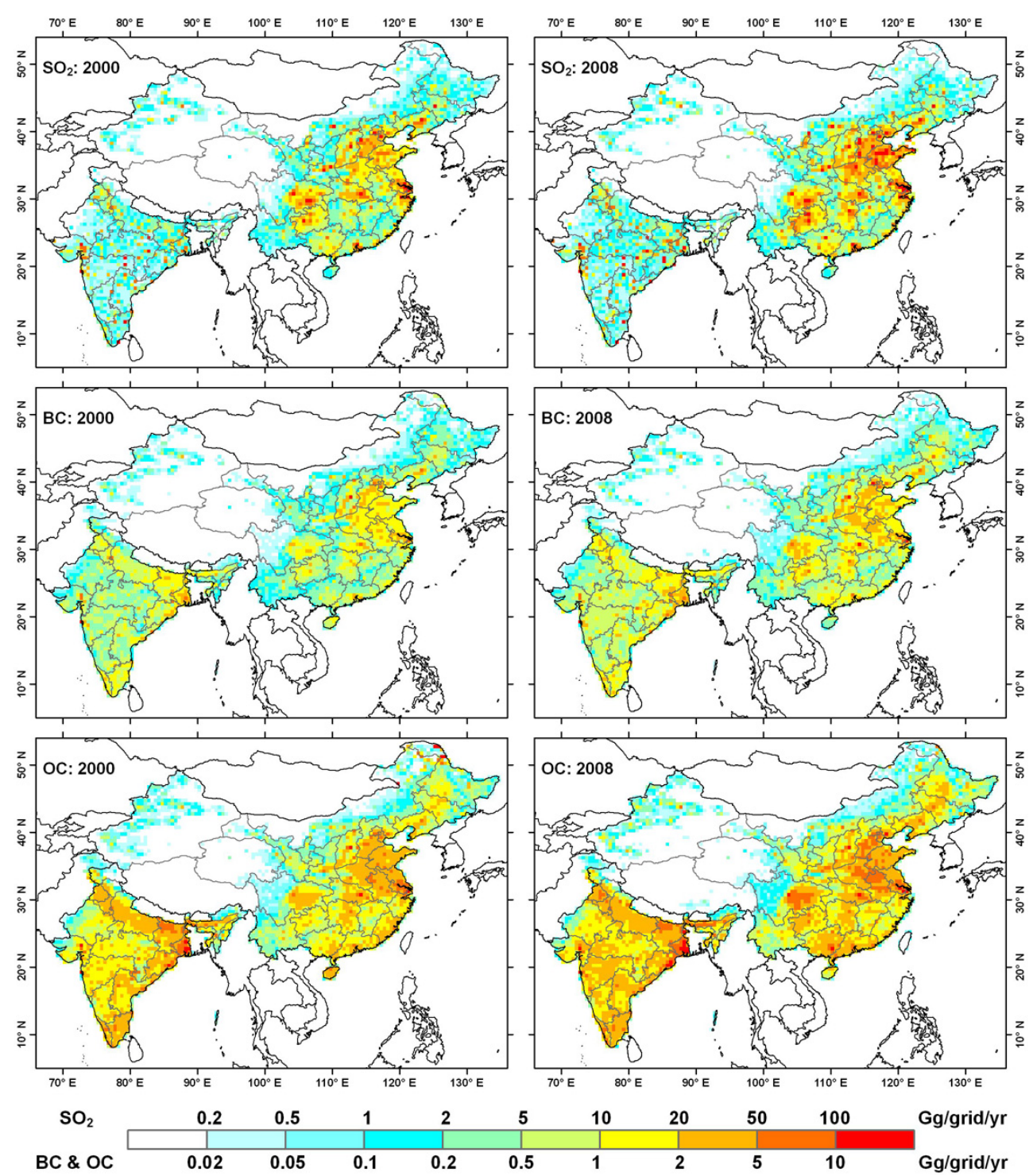

Fig. 8. Emission distributions of $\mathrm{SO}_{2}, \mathrm{BC}$, and $\mathrm{OC}$ at $0.5^{\circ} \times 0.5^{\circ}$ resolution in 2000 and 2008 . International shipping and aviation are not included.

$-70 \%-329 \%$ for OC), Bond et al. (2004) (-36\%-149\% for BC and $-44 \%-103 \%$ for OC), and Zhao et al. (2011) $(-25 \%-136 \%$ for BC and $-40 \%-121 \%$ for OC). For India, our results $(-41 \%-87 \%$ for $\mathrm{BC}$ and $-44 \%-92 \%$ for OC) are also lower than the estimations of TRACE-P (-78\%$459 \%$ for BC and $-84 \%-644 \%$ for OC) and Bond et al. (2004) $(-38 \%-119 \%$ for BC and $-43 \%-93 \%$ for OC). The following reasons may be attributed to the reduction of uncertainties. First, we applied the Monte Carlo approach to our detailed technology-based emission model, and the "compensation-of-error" mechanism of Monte Carlo simulation can reduce random errors significantly (Zhao et al., 2011). Second, in the present work, we obtained more detailed information about the technology distribution, activity rate, and emission characteristic for both China and In- dia. Third, some newly developed methodologies or inventories were incorporated, e.g., the GFED3.1 inventory, unitbased power-plant emission inventories, newly estimated Indian biofuel consumption, etc.

\subsubsection{Constraints from observations and models}

Bottom-up emission inventories can be evaluated, constrained, and improved by observations directly (including ground-, aircraft-, and balloon-based measurements and satellite retrievals) or by the forward or inverse modeling of these observations. In previous work, we compared the $\mathrm{SO}_{2}$ emissions in China with a variety of observed sulfur related quantities over East Asia, including $\mathrm{SO}_{2}$ and $\mathrm{SO}_{4}^{2-}$ concentrations, surface solar radiation, and AOD (Lu et al., 

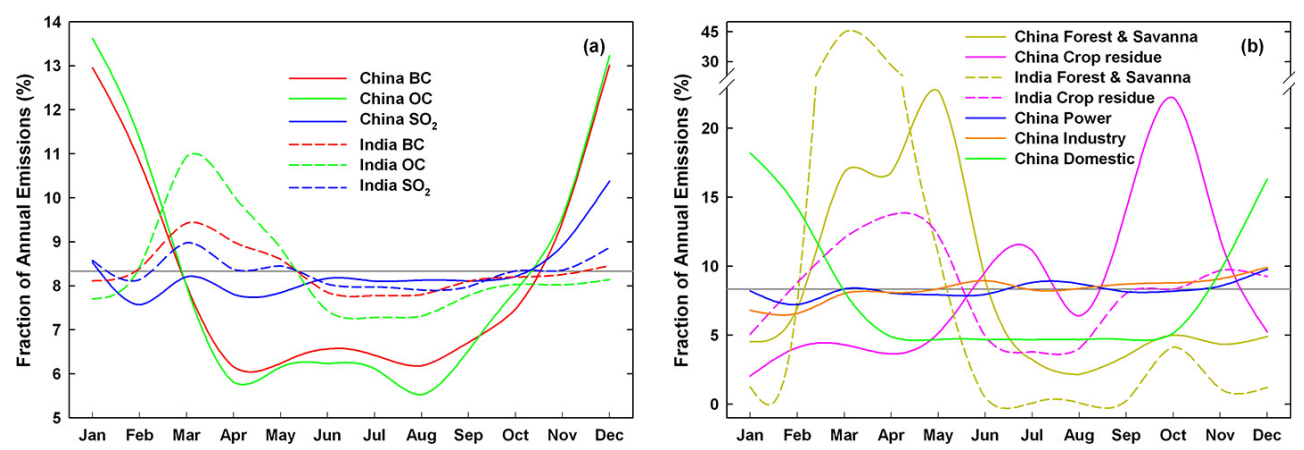

Fig. 9. Average seasonality of $\mathrm{SO}_{2}, \mathrm{BC}$, and $\mathrm{OC}$ emissions (a) and monthly profiles of major sectors (b) in China and India during 19962010.

2010). We found the trends of these observations are generally consistent with the trend of our $\mathrm{SO}_{2}$ emission estimates during 2000-2008. Van Donkelaar et al. (2008) analyzed AOD data from MISR and MODIS for 2000-2006 with the GEOS-Chem model. They derived the annual growth in Chinese sulfur emissions to be $6.2 \%$ and $9.6 \%$, respectively, which is in good agreement with our current work $(8.2 \%)$. Aikawa et al. (2010) compared the measured sulfate concentration at multiple sites over the East Asia Pacific Rim region with CMAQ model simulations using both the REAS and the China MEP $\mathrm{SO}_{2}$ inventories. They concluded that the REAS inventory overestimates, whereas the China MEP inventory underestimates the $\mathrm{SO}_{2}$ emissions from China. Our central estimates as well as uncertainty ranges fall in the middle of these two inventories. During the TRACE-P and the ACEAsia field experiments, intensive measurements were used in conjunction with forward and inverse modeling analysis to evaluate emission estimates for Asia. The results indicated that $\mathrm{SO}_{2}$ emissions in the TRACE-P inventory are reasonable (Carmichael et al., 2003; Russo et al., 2003), while BC emissions are qualitatively correct at the national level, but the spatial distributions are questionable (Carmichael et al., 2003; Hakami et al., 2005). Recently, Kondo et al. (2011) estimated the $\mathrm{BC}$ emission rate of China by comparing $\mathrm{BC}$ concentrations observed at a remote site in the East China Sea and those predicted by 3-D chemical transport models. They derived the annually averaged BC emission flux over China to be $1.92 \mathrm{Tg}$ with an uncertainty of about $40 \%$ during 2008-2009. This value is very close to our estimation of $1.79 \mathrm{Tg}$ with an uncertainty of $-41 \%-84 \%$ in 2008.

\subsection{Gridded emissions}

Figures $\mathrm{S} 1-\mathrm{S} 3$ in the Supplement show the spatial distributions of $\mathrm{SO}_{2}, \mathrm{BC}$, and $\mathrm{OC}$ emissions in China and India at a resolution of $0.1^{\circ} \times 0.1^{\circ}$ in $1996,2000,2005$, and 2010 . The annual gridded emissions data by sector are available from the corresponding author. To present the emissions from LPSs more clearly (especially for $\mathrm{SO}_{2}$ emissions from power plants), we give the emission distributions at a resolution of $0.5^{\circ} \times 0.5^{\circ}$ in Fig. 8. As shown in Fig. 8, a significant increase of emissions can be seen in both countries between 2000 and 2008. For $\mathrm{SO}_{2}$, emission fluxes are high at grids with power plants and industrialized city clusters (e.g., eastern central China and Sichuan Basin). More $\mathrm{SO}_{2}$ hot spots are observed in China than in India during 2000-2008 because the increase of thermal based electricity generation in China was realized by building new power plants - often in undeveloped parts of the country - whereas that in India was realized by increasing the capacities of existing plants. Compared to $\mathrm{SO}_{2}$, high emission regions of carbonaceous aerosols are not concentrated in hot spots, but spread across eastern and central China and the northern and eastern states of India where rural population densities are high and residential coal and biofuel combustion are prevalent.

\subsection{Seasonality of emissions}

Figure 9 presents the average seasonality of $\mathrm{SO}_{2}, \mathrm{BC}$, and OC emissions, as well as sectors with significant monthly variations (maxima/minima $>1.2$ ) in China and India. Biomass burning of forest and savanna occurs usually in February-June for both countries, and that of crop waste burning peaks in July and October for China, and April and September-November for India, corresponding to the major harvest seasons. Residential emissions in China are higher in December, January and February due to residential heating needs in winter. Significant monthly variations are also found in the power and industry sectors of China. Emissions are higher in December and lower in February, with maxima-to-minima ratios of 1.4 and 1.5 for the power and industry sectors, respectively. Regarding the seasonality of each species, it is a combination of sectoral emissions on the basis of their weight contribution to the total emissions. The ratios of monthly $\mathrm{SO}_{2}, \mathrm{BC}$, and $\mathrm{OC}$ emissions between maxima and minima are 1.4, 2.1, and 2.5 for China, and 1.1, 1.2, and 1.5 for India (Fig. 9a). 

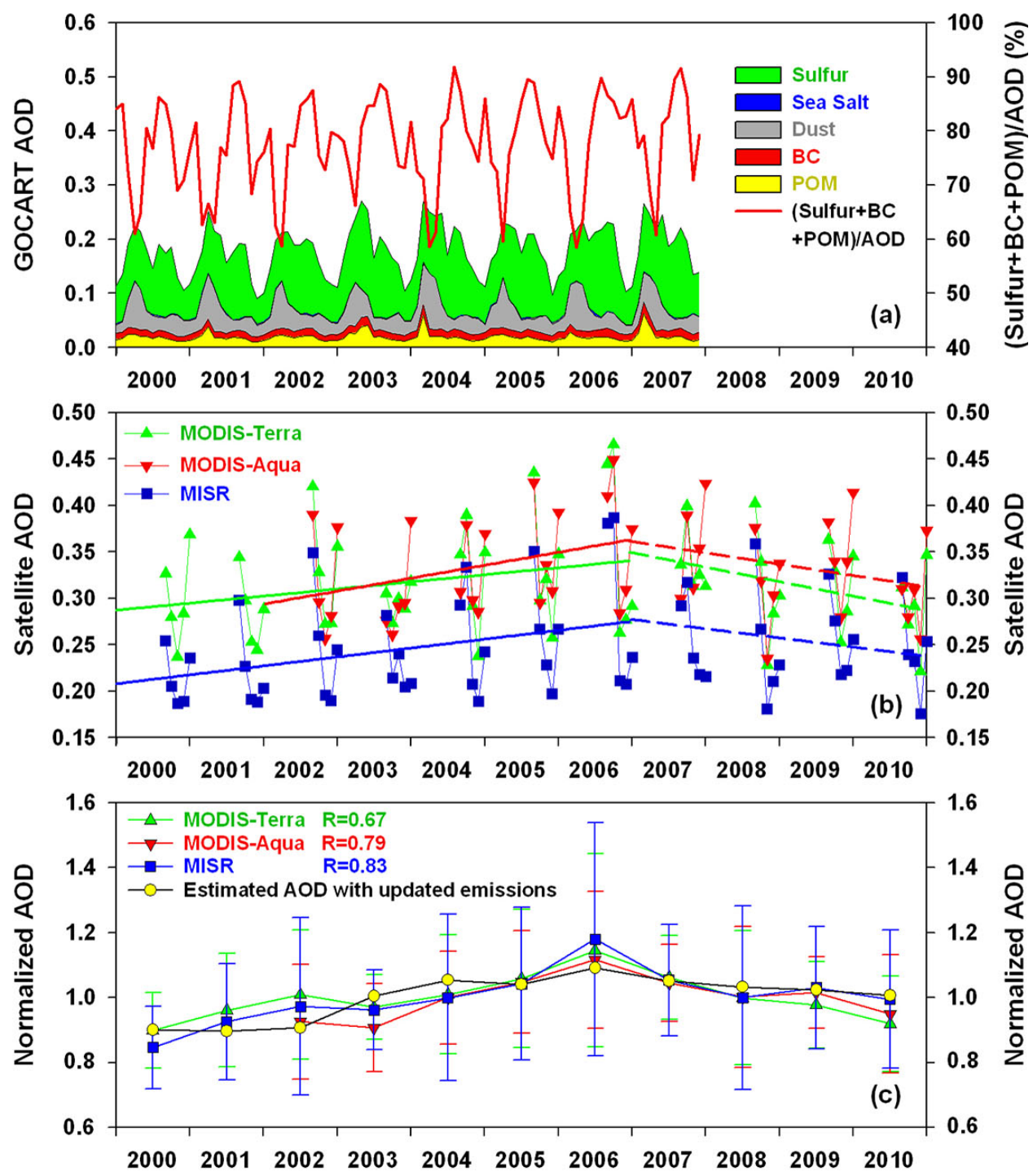

Fig. 10. AOD from GOCART model simulations and the MODIS (Terra and Aqua) and MISR satellite instruments over eastern central China (latitude $<45^{\circ} \mathrm{N}$, longitude $>100^{\circ} \mathrm{E}$ ). (a) Monthly variation of GOCART AOD and the combined contribution from sulfate, BC, and POM to total AOD during 2000-2007. (b) Monthly mean variability of satellite AOD retrievals during September to January 2000-2010. Solid and dashed lines represent the linear tendencies before and after 2006, respectively. (c) Trend of estimated $\mathrm{AOD}_{\mathrm{O}}$ due to $\mathrm{SO}_{2}$, $\mathrm{BC}$, and OC emissions, and evolutions of satellite AOD averaged between September and January during 2000-2010. $R$ values shown are the correlation coefficients of each satellite AOD with estimated AOD. Error bars express one standard deviation of the monthly mean.

\section{Comparison of emission estimates and satellite observations}

As mentioned in Sect. 3.3.3, observations from field measurements and satellites can be used directly to constrain bottom-up emission inventories. Comparing with ground-, aircraft-, and balloon-based measurements, satellite observations provide better temporal sampling and spatial coverage. In the following section, we will use satellite retrievals of $\mathrm{AOD}$ and $\mathrm{SO}_{2}$ to verify the emission trends of this study.

\subsection{AOD}

AOD is strongly influenced by the natural particulate component (e.g., dust and sea salt) in China and India (Chin et al., 2009; Streets et al., 2009). To compare the satellite AOD and our emission estimates, the first step is to identify the months in which anthropogenic emissions have the greatest impact on AOD. Figures 10a and 11a show the monthly AOD variations of the major aerosol components over eastern central China (latitude $<45^{\circ} \mathrm{N}$, longitude $>100^{\circ} \mathrm{E}$ ) and India from GOCART model simulations. For eastern central China, dust (originating mainly from the Taklimakan Desert 

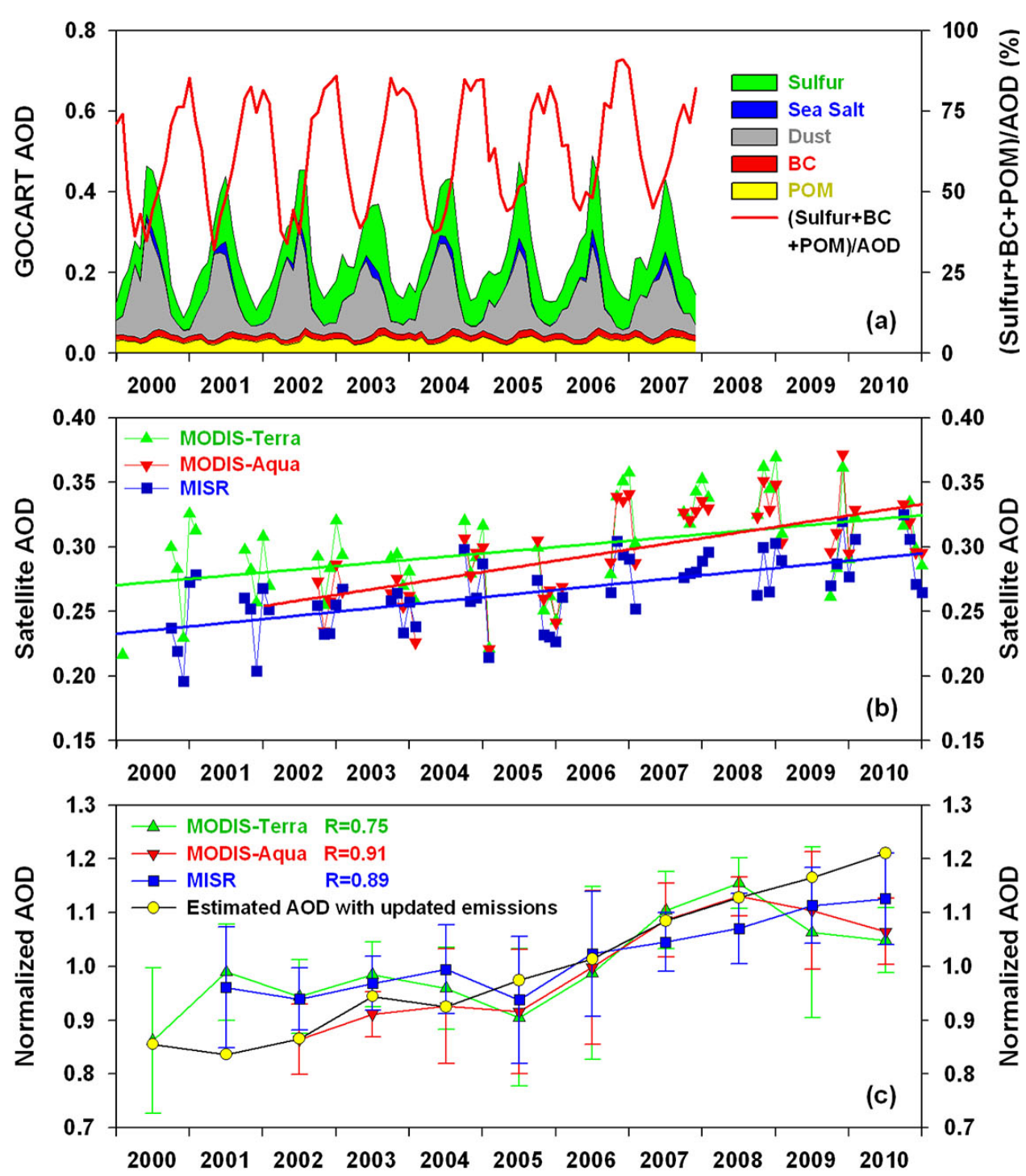

Fig. 11. AOD from GOCART model simulations and the MODIS (Terra and Aqua) and MISR satellite instruments over India. (a) Monthly variation of GOCART AOD and the combined contribution from sulfate, BC, and POM to total AOD during 2000-2007. (b) Monthly mean variability of satellite AOD retrievals during October to February 2000-2010. Solid lines represent the linear tendencies. (c) Trend of estimated $\mathrm{AOD}$ due to $\mathrm{SO}_{2}, \mathrm{BC}$, and $\mathrm{OC}$ emissions, and evolutions of satellite AOD averaged between October and February during 2000-2010. $R$ values shown are the correlation coefficients of each satellite AOD with estimated AOD. Error bars express one standard deviation of the monthly mean.

and the Gobi Desert) comprises a large fraction of AOD in spring (March-May, 33\%). The combined contribution from sulfate, $\mathrm{BC}$, and primary organic matter (POM) to total AOD is high during June-January, accounting for $82 \%$ of total AOD. To minimize the potential effect of biomass burning of forest and savanna in summer (June-August), we select September-January as our study period for China. In India, the monsoon meteorology can be divided into four basic periods: winter (December-February), summer/pre-monsoon (March-June), monsoon (late June-September), and postmonsoon (October-November). Since the transportation of mineral dust from Iran, Afghanistan, and the Thar Desert in western India is pronounced during summer and monsoon months (Kharol et al., 2011; Prasad and Singh, 2007), October-February is selected as our study period for India (the average combined contribution from sulfate, $\mathrm{BC}$, and POM to AOD is $79 \%$ ).

Figures $10 \mathrm{~b}$ and $11 \mathrm{~b}$ show the temporal variation of monthly AOD values averaged over eastern central China and India, respectively, from Terra/MODIS, Aqua/MODIS, and MISR satellite retrievals during the selected study periods. Generally, Terra/MODIS has higher AOD values over China and India, while values of MISR AOD are lower. The correlations between the three datasets are high 
( $R=0.87-0.95$ for China, and $0.95-0.97$ for India). All these findings are consistent with previous studies (Ahn et al., 2008; Kharol et al., 2011; Prasad and Singh, 2007). The discrepancies between different instruments may be caused by the satellite characteristics, detection principle, measurement time, retrieval algorithms, etc. The annual averages, as well as the standard deviations of the monthly AOD, are shown in Figs. 10c and 11c. Figures $10 \mathrm{c}$ and $11 \mathrm{c}$ also show the trends of estimated AOD due to $\mathrm{SO}_{2}, \mathrm{BC}$, and $\mathrm{OC}$ emissions in both countries. In our previous work, we established a linear relationship between AOD and the emission strengths of the various aerosol precursors from a single-year (year 2001) run of the GOCART model (Streets et al., 2009). In this study, we follow a similar methodology, but use the results from multiple-year (2000-2007), full runs of the GOCART model for the purpose of capturing any year-to-year variability of the relationships that might arise from long-term changes in meteorology, chemistry, transport, etc. AOD value due to species $j$ in country $i$ for year $t$ is calculated by:

$\mathrm{AOD}_{j, i, t}=f_{j, i, t} \cdot \mathrm{Em}_{j, i, t}$

where Em is the annual emission rate, and $f$ is a linear conversion factor between the GOCART AOD and the emission mass. For years 2008-2010, average $f$ values between 2000 and 2007 were used. It should be noted that other natural emissions contributing to the $\mathrm{SO}_{2}, \mathrm{BC}$, and $\mathrm{OC}$ emissions in China and India (e.g., biogenic, volcanic, and DMS emissions) were also considered in the calculation, although they are very small compared to anthropogenic and biomass burning emissions.

As shown in Figs. 10c and 11c, the trends of estimated AOD due to $\mathrm{SO}_{2}, \mathrm{BC}$, and $\mathrm{OC}$ emissions are in good agreement with the trends of AOD satellite retrievals in both China and India during the selected study periods $(R=0.67-0.83$ for China, and 0.75-0.91 for India). This suggests a close relationship between AOD and emissions of aerosols and their precursors. For eastern central China, AOD retrievals from three instruments were increasing during 2000-2006, corresponding to the dramatic increase of emissions in China (Aqua/MODIS and MISR have statistically significant trends at a $95 \%$ confidence level). The AGRs are $4.1 \%, 4.8 \%$, and $5.7 \%$ for Terra/MODIS, Aqua/MODIS, and MISR, respectively, and are in line with the rates of $3.4 \%-4.1 \%$ reported by van Donkelaar et al. (2008). After 2006, the decreasing tendency of satellite AOD retrievals in China also corresponds well with our estimated AOD, which is based on the current emission estimates (Terra/MODIS has a statistically significant trend at a $95 \%$ confidence level). The decline is mainly attributed to the pronounced decrease of $\mathrm{SO}_{2}$ emissions in China and the dominant role of sulfate in AOD (62\%, Fig. 10a). For India, although there is some interannual variation, AOD values from different datasets were continuously increasing during the last decade, with AGRs of $2.0 \%, 3.5 \%, 2.5 \%$, and $3.5 \%$ for Terra/MODIS,

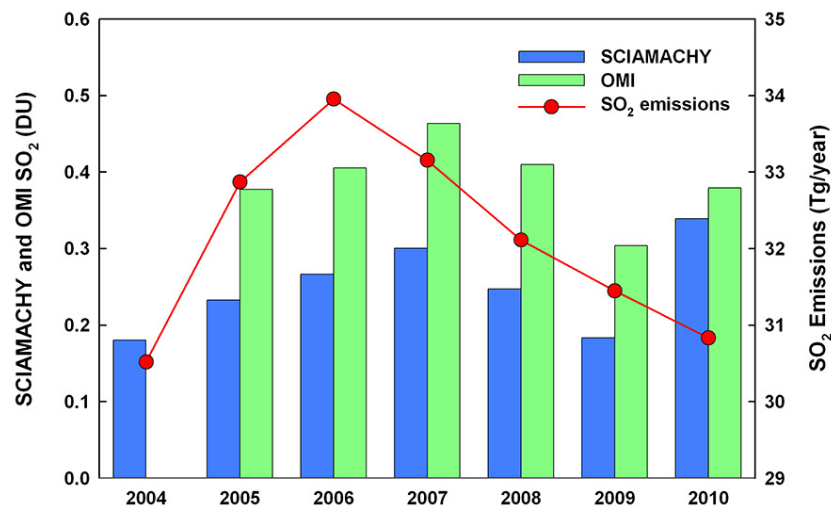

Fig. 12. $\mathrm{SO}_{2}$ emissions in China and annual average $\mathrm{SO}_{2}$ column from SCIAMACHY and OMI over eastern central China during 2004-2010.

Aqua/MODIS, MISR, and our estimated AOD, respectively. All the linear tendencies in Fig. 11b are statistically significant at a $95 \%$ confidence level. This result is qualitatively and quantitatively in line with several Indian studies. For example, Prasad and Singh (2007) compared the AOD retrievals of both MISR and Terra/MODIS over the IndoGangetic basin and observed an increase in satellite-derived aerosol loading over major cities for the 2000-2005 winter and summer seasons. Kharol et al. (2011) found that AOD values over the urban region of Hyderabad from both Terra/MODIS and Aqua/MODIS show increasing trends in the period 2002-2008 with AGRs of $3.0 \%$ and $4.4 \%$ for Terra/MODIS and Aqua/MODIS, respectively. All these imply an increase in emissions driven by the growth of economic, energy consumption, and population in India after 2000.

\section{2 $\mathrm{SO}_{2}$}

Due to the low sensitivity, the early remote sensing instruments were only able to monitor and quantify $\mathrm{SO}_{2}$ emissions from exceptional pollution events such as volcanic eruptions. However, the sensitivity improvement of the current generation of instruments (e.g., SCIAMACHY and OMI) makes it possible to identify strong anthropogenic $\mathrm{SO}_{2}$ signals from LPSs (e.g., smelters and coal-fired power plants) or industrial regions (e.g., China) (Krotkov et al., 2008; Lee et al., 2009). In this section, we compare our $\mathrm{SO}_{2}$ emission trend with trends of $\mathrm{SO}_{2}$ columns retrieved from satellites in eastern central China; unfortunately, $\mathrm{SO}_{2}$ signals over India are too low to give reliable data at this time. Figure 12 shows the annual average $\mathrm{SO}_{2}$ column from SCIAMACHY and OMI over eastern central China during 2004-2010. It should be noted that, although OMI columns appear to be higher than SCIAMACHY columns, they use different AMF values (Sect. 2.4). Recently, Lee et al. (2009) developed a local AMF algorithm by using $\mathrm{SO}_{2}$ and aerosol profiles simulated 
in a GEOS-Chem model. They suggested a seasonal average AMF of about 0.5 over China. Applying this factor, the SCIAMACHY columns tend to be 0.6 DU higher than OMI columns, which is consistent with the finding of Lee et al. (2009) (0.4-0.7 DU over east China).

As shown in Fig. 12, the increase of $\mathrm{SO}_{2}$ emissions before 2006 and the decrease of $\mathrm{SO}_{2}$ emissions after 2007 are captured in the trends of $\mathrm{SO}_{2}$ columns observed by both the SCIAMACHY and the OMI instruments. However, there are some discrepancies between the trends of emissions and observations. For example, satellite observations peak in 2007, whereas $\mathrm{SO}_{2}$ emission in China peaks in 2006; and $\mathrm{SO}_{2}$ emissions are estimated to continue to decrease in 2010, whereas $\mathrm{SO}_{2}$ retrievals seem to suggest an increase. It is really hard to tell the exact reasons for these discrepancies since both emission estimates and satellite retrievals contain substantial uncertainties. From the perspective of the emission inventory, national $\mathrm{SO}_{2}$ emissions are sensitive to the actual FGD removal efficiency, especially for the year 2007 (16\% of the variances, Fig. 7a). As mentioned in Sect. 3.2, the China MEP reported a $\mathrm{SO}_{2}$ removal rate of $73.2 \%$ in 2007 for FGD equipped power plants, whereas this rate was only $64.1 \%$ in Jiangsu province, which has a relatively good track record on environmental protection (Xu et al., 2009). If the actual FGD removal efficiency was $10 \%$ lower than the value reported by the China MEP (i.e., $63 \%$ ), $\mathrm{SO}_{2}$ emissions from China in 2007 would reach $34.2 \mathrm{Tg}$, higher than the estimated emissions in 2006. On the other hand, the retrieved $\mathrm{SO}_{2}$ columns also contains large uncertainties, which are related to cloud cover, viewing geometry, $\mathrm{SO}_{2}$ profile (shape factor), and aerosol loading, as well as interference by the absorption signals of ozone (Krotkov et al., 2008; Lee et al., 2009). The influence of cloud cover on AMF was believed to be minimized by filtering the daily retrievals with high radiative cloud fraction ( $>0.3$, see Sect. 2.4). Parameters such as $\mathrm{SO}_{2}$ profile and viewing geometry have either relatively small effect on AMF correction over China or negligible change over time (Krotkov et al., 2008). However, AMF uncertainties from aerosols might be very high over polluted regions (Lee et al., 2009). Krotkov et al. (2008) reported that the presence of UV absorbing aerosols (e.g., dust and secondary organic aerosol, SOA) in China would reduce the AMF by half and double the retrieved $\mathrm{SO}_{2}$. A reduction of aerosol absorption over Beijing since 2007 has been reported through an analysis of observations of MODIS and AERONET AOD, and long-term measurements of PM chemical composition in Beijing (Lyapustin et al., 2011). Hence, if absorbing aerosol loading over China in 2010 was significantly lower than in previous years, it would be possible to obtain lower corrected $\mathrm{SO}_{2}$ columns.

In addition, the change of $\mathrm{SO}_{2}$ atmospheric chemistry could also affect the relationship between emissions and observations. Using a global chemistry and aerosol model, Manktelow et al. (2007) found that the surface sulfate concentration over East Asia increased at a greater rate than the $\mathrm{SO}_{2}$ emission, whereas the surface $\mathrm{SO}_{2}$ concentration increased at a lower rate. This conclusion was later confirmed by our analysis of $\mathrm{SO}_{2}$ and sulfate concentration monitored in Japan and Korea (Lu et al., 2010), indicating that East Asia is a less oxidant-limited area than other areas in the world. In the past few years, the Chinese government has implemented a series of air pollution control measures, especially during preparations for the Beijing Olympic Games, and the primary air pollutants as well as $\mathrm{SO}_{2}$ oxidants such as $\mathrm{OH}, \mathrm{H}_{2} \mathrm{O}_{2}$, and $\mathrm{O}_{3}$ have been reported to significantly decrease (e.g., He et al., 2010; Wang et al., 2009). Hence, it is possible that the conversion efficiency of $\mathrm{SO}_{2}$ to sulfate decreased over China in recent years, and thus gaseous $\mathrm{SO}_{2}$ was preferentially accumulated in the atmosphere.

\section{Summary and conclusions}

In the present work, we use a detailed technology-based methodology to estimate historical $\mathrm{SO}_{2}$ and primary carbonaceous aerosol (i.e., $\mathrm{BC}$ and $\mathrm{OC}$ ) emissions in China and India during the period 1996-2010. Emission sources are categorized into five major sectors: power generation, industry, residential, transportation, and open biomass burning. Time-dependent trends in activity rates, technology penetration, and emission factors are incorporated into the calculations to reflect the rapid increase of energy consumption and the dramatic changes in technology distribution and hence emission factors during this period. Emissions are gridded at a resolution of $0.1^{\circ} \times 0.1^{\circ}$ using year-by-year spatial proxies and related datasets. In addition, year-specific monthly temporal distributions for $\mathrm{SO}_{2}, \mathrm{BC}$, and $\mathrm{OC}$ emissions from each major sector during 1996-2010 are developed. All of the input parameters and their corresponding probability distributions are incorporated into a Monte Carlo framework to determine the uncertainties of emissions. Sensitivity analysis is conducted to identify the major contributors to the emission uncertainties. Satellite retrievals of AOD (from Terra/MODIS, Aqua/MODIS, and MISR) and $\mathrm{SO}_{2}$ (from SCIAMACHY and OMI) are used to verify the bottom-up emission trends, and good agreement is found.

China and India are the two largest national contributors to the global anthropogenic aerosol budget. Our results indicate very high growth of $\mathrm{SO}_{2}, \mathrm{BC}$, and $\mathrm{OC}$ emissions in both countries during the study period. Between 1996 and 2010, emissions growth in China was $27 \%$ for $\mathrm{SO}_{2}, 21 \%$ for $\mathrm{BC}$, and $21 \%$ for OC, with periods of greater and lesser growth during the entire timeframe. Emissions growth in India over the same period was $70 \%$ for $\mathrm{SO}_{2}, 41 \%$ for $\mathrm{BC}$, and $35 \%$ for $\mathrm{OC}$, at a steady pace throughout the period. Other things being equal, it can be expected that similar increases will have occurred in ambient concentrations, deposition, and transport of these species. As a consequence, significant impacts on human health, air quality, atmospheric physics and chemistry, climate forcing, hydrological cycles, and ecosystems at 
local-, regional-, and global scales will have occurred. The emission trends and annually gridded datasets developed in the current work can be used by regional and global models to address these associated issues and help us to better understand the effects of intensive release of aerosols (and their precursors) on the environment during this period of rapid economic development. Additionally, the Monte Carlo uncertainty analysis provided in this work makes it possible for modelers to estimate uncertainties in, for example, aerosol radiative forcing due to uncertainties in aerosol emissions.

\section{Supplement related to this article is available online at: http://www.atmos-chem-phys.net/11/9839/2011/ acp-11-9839-2011-supplement.pdf.}

Acknowledgements. This work was primarily funded by the Modeling, Analysis and Predictability (MAP) program of the National Aeronautics and Space Administration (NASA) under Proposal No. 08-MAP-0143, for which we thank David Considine (NASA) and Mian Chin (NASA Goddard Space Flight Center). The India component of the work was partially funded in support of the Ganges Valley Aerosol Experiment (GVAX) by the Office of Biological and Environmental Research in the US Department of Energy Office of Science, for which we are grateful to Ashley Williamson and Bob Vallario. We also thank Professor Tami Bond of the University of Illinois at Urbana-Champaign for providing helpful data sets. Argonne National Laboratory is operated by UChicago Argonne, LLC, under Contract No. DE-AC02-06CH11357 with the US Department of Energy.

Edited by: M. Kopacz

\section{References}

Ahn, C., Torres, O., and Bhartia, P. K.: Comparison of ozone monitoring instrument UV aerosol products with Aqua/Moderate Resolution Imaging Spectroradiometer and Multiangle Imaging Spectroradiometer observations in 2006, J. Geophys. Res., 113, D16S27, doi:10.1029/2007jd008832, 2008.

Aikawa, M., Ohara, T., Hiraki, T., Oishi, O., Tsuji, A., Yamagami, M., Murano, K., and Mukai, H.: Significant geographic gradients in particulate sulfate over Japan determined from multiple-site measurements and a chemical transport model: Impacts of transboundary pollution from the Asian continent, Atmos. Environ., 44, 381-391, 2010.

Akimoto, H., Ohara, T., Kurokawa, J., and Horii, N.: Verification of energy consumption in China during 1996-2003 by using satellite observational data, Atmos. Environ., 40, 7663-7667, 2006.

Andreae, M. O. and Merlet, P.: Emission of trace gases and aerosols from biomass burning, Global Biogeochem. Cy., 15, 955-966, 2001.

Bond, T. C., Streets, D. G., Yarber, K. F., Nelson, S. M., Woo, J. H., and Klimont, Z.: A technology-based global inventory of black and organic carbon emissions from combustion, J. Geophys. Res., 109, D14203, doi:10.1029/2003jd003697, 2004.

Bond, T. C., Bhardwaj, E., Dong, R., Jogani, R., Jung, S. K., Roden, C., Streets, D. G., and Trautmann, N. M.: Historical emissions of black and organic carbon aerosol from energy-related combustion, 1850-2000, Global Biogeochem. Cy., 21, GB2018, doi:10.1029/2006gb002840, 2007.

Cao, G. L., Zhang, X. Y., and Zheng, F. C.: Inventory of black carbon and organic carbon emissions from China, Atmos. Environ., 40, 6516-6527, 2006.

Carmichael, G. R., Tang, Y., Kurata, G., Uno, I., Streets, D. G., Thongboonchoo, N., Woo, J. H., Guttikunda, S., White, A., Wang, T., Blake, D. R., Atlas, E., Fried, A., Potter, B., Avery, M. A., Sachse, G. W., Sandholm, S. T., Kondo, Y., Talbot, R. W., Bandy, A., Thorton, D., and Clarke, A. D.: Evaluating regional emission estimates using the TRACE-P observations, J. Geophys. Res., 108(D21), 8810, doi:10.1029/2002jd003116, 2003.

Center for International Earth Science Information Network (CIESIN), Columbia University, International Food Policy Research Institute (IFPRI), The World Bank, and Centro Internacional de Agricultura Tropical (CIAT): Global Rural-Urban Mapping Project (GRUMP), Alpha Version: Urban Extents, Socioeconomic Data and Applications Center (SEDAC), Columbia University, Palisades, NY, USA, 2004.

Central Electricity Authority (CEA): Performance review of thermal power stations 1999-2009, Ministry of Power, R K Puram, New Delhi, 2000-2010.

Central Statistical Organization (CSO): Monthly Abstract of Statistics 2000-2010, Ministry of Statistics and Programme Implementation, Government of India, New Delhi, 2000-2010.

Chen, Y. J., Zhi, G. R., Feng, Y. L., Liu, D. Y., Zhang, G., Li, J., Sheng, G. Y., and Fu, J. M.: Measurements of black and organic carbon emission factors for household coal combustion in China: implication for emission reduction, Environ. Sci. Technol., 43, 9495-9500, 2009.

Chin, M., Diehl, T., Dubovik, O., Eck, T. F., Holben, B. N., Sinyuk, A., and Streets, D. G.: Light absorption by pollution, dust, and biomass burning aerosols: a global model study and evaluation with AERONET measurements, Ann. Geophys., 27, 3439-3464, doi:10.5194/angeo-27-3439-2009, 2009.

Defense Mapping Agency (DMA): Digital Chart of the World Database, Washington DC, USA, 1993.

Dickerson, R. R., Andreae, M. O., Campos, T., Mayol-Bracero, O. L., Neusuess, C., and Streets, D. G.: Analysis of black carbon and carbon monoxide observed over the Indian Ocean: Implications for emissions and photochemistry, J. Geophys. Res., 107, 8017, doi:10.1029/2001jd000501, 2002.

Garg, A., Shukla, P. R., and Kapshe, M.: The sectoral trends of multigas emissions inventory of India, Atmos. Environ., 40, 4608-4620, 2006

Goldewijk, K. K., Beusen, A., van Drecht, G., and de Vos, M.: The HYDE 3.1 spatially explicit database of human-induced global land-use change over the past 12,000 years, Global Ecol. Biogeogr., 20, 73-86, 2011.

Habib, G., Venkataraman, C., Shrivastava, M., Banerjee, R., Stehr, J. W., and Dickerson, R. R.: New methodology for estimating biofuel consumption for cooking: Atmospheric emissions of black carbon and sulfur dioxide from India, Global Biogeochem. Cy., 18, GB3007, doi:10.1029/2003gb002157, 2004.

Habib, G., Venkataraman, C., Bond, T. C., and Schauer, J. J.: Chemical, microphysical and optical properties of primary particles from the combustion of biomass fuels, Environ. Sci. Technol., 42, 8829-8834, 2008.

Hakami, A., Henze, D. K., Seinfeld, J. H., Chai, T., Tang, Y., 
Carmichael, G. R., and Sandu, A.: Adjoint inverse modeling of black carbon during the Asian Pacific Regional Aerosol Characterization Experiment, J. Geophys. Res., 110, D14301, doi:10.1029/2004jd005671, 2005.

He, K. B., Huo, H., Zhang, Q., He, D. Q., An, F., Wang, M., and Walsh, M. P.: Oil consumption and $\mathrm{CO}_{2}$ emissions in China's road transport: current status, future trends, and policy implications, Energ. Pol., 33, 1499-1507, 2005.

He, S. Z., Chen, Z. M., Zhang, X., Zhao, Y., Huang, D. M., Zhao, J. N., Zhu, T., Hu, M., and Zeng, L. M.: Measurement of atmospheric hydrogen peroxide and organic peroxides in Beijing before and during the 2008 Olympic Games: Chemical and physical factors influencing their concentrations, J. Geophys. Res., 115, D17307, doi:10.1029/2009jd013544, 2010.

International Energy Agency (IEA): Energy Statistics of NonOECD Countries, Paris, France, 2010.

Joint Research Centre (JRC)/Netherlands Environmental Assessment Agency (PBL): Emission Database for Global Atmospheric Research (EDGAR), release version 4.1, available online at: http://edgar.jrc.ec.europa.eu, last access: 15 June 2011, 2010.

Kahn, R. A., Gaitley, B. J., Martonchik, J. V., Diner, D. J., Crean, K. A., and Holben, B.: Multiangle Imaging Spectroradiometer (MISR) global aerosol optical depth validation based on 2 years of coincident Aerosol Robotic Network (AERONET) observations, J. Geophys. Res., 110, D10S04, doi:10.1029/2004jd004706, 2005.

Kharol, S. K., Badarinath, K. V. S., Sharma, A. R., Kaskaoutis, D. G., and Kambezidis, H. D.: Multiyear analysis of Terra/Aqua MODIS aerosol optical depth and ground observations over tropical urban region of Hyderabad, India, Atmos. Environ., 45, 1532-1542, 2011.

Klimont, Z., Cofala, J., Xing, J., Wei, W., Zhang, C., Wang, S., Kejun, J., Bhandari, P., Mathur, R., Purohit, P., Rafaj, P., Chambers, A., and Amann, M.: Projections of $\mathrm{SO}_{2}, \mathrm{NO}_{\mathrm{x}}$ and carbonaceous aerosols emissions in Asia, Tellus B, 61, 602-617, 2009.

Kondo, Y., Oshima, N., Kajino, M., Mikami, R., Moteki, N., Takegawa, N., Verma, R. L., Kajii, Y., Kato, S., and Takami, A.: Emissions of black carbon in East Asia estimated from observations at a remote site in the East China Sea, J. Geophys. Res., 116, D16201, doi:10.1029/2011JD015637, 2011.

Krotkov, N. A., McClure, B., Dickerson, R. R., Carn, S. A., Li, C., Bhartia, P. K., Yang, K., Krueger, A. J., Li, Z. Q., Levelt, P. F., Chen, H. B., Wang, P. C., and Lu, D. R.: Validation of $\mathrm{SO}_{2}$ retrievals from the Ozone Monitoring Instrument over NE China, J. Geophys. Res., 113, D16s40, doi:10.1029/2007jd008818, 2008.

Lee, C., Martin, R. V., van Donkelaar, A., O’Byrne, G., Krotkov, N., Richter, A., Huey, L. G., and Holloway, J. S.: Retrieval of vertical columns of sulfur dioxide from SCIAMACHY and OMI: Air mass factor algorithm development, validation, and error analysis, J. Geophys. Res., 114, D22303, doi:10.1029/2009jd012123, 2009.

Lei, Y., Zhang, Q., He, K. B., and Streets, D. G.: Primary anthropogenic aerosol emission trends for China, 1990-2005, Atmos. Chem. Phys., 11, 931-954, doi:10.5194/acp-11-931-2011, 2011.

Li, X. H., Wang, S. X., Duan, L., Hao, J. M., and Nie, Y. F.: Carbonaceous aerosol emissions from household biofuel combustion in China, Environ. Sci. Technol., 43, 6076-6081, 2009.

Lu, Z., Streets, D. G., Zhang, Q., Wang, S., Carmichael, G. R., Cheng, Y. F., Wei, C., Chin, M., Diehl, T., and Tan, Q.: Sulfur dioxide emissions in China and sulfur trends in East Asia since 2000, Atmos. Chem. Phys., 10, 6311-6331, doi:10.5194/acp-106311-2010, 2010.

Lyapustin, A., Smirnov, A., Holben, B., Chin, M., Streets, D. G., Lu, Z., Kahn, R., Slutsker, I., Laszlo, I., Kondragunta, S., Tanre, D., Dubovik, O., Goloub, P., Chen, H.-B., Sinyuk, A., Wang, Y., and Korkin, S.: Reduction of aerosol absorption in Beijing since 2007 from MODIS and AERONET, Geophys. Res. Lett., 38, L10803, doi:10.1029/2011g1047306, 2011.

Manktelow, P. T., Mann, G. W., Carslaw, K. S., Spracklen, D. V., and Chipperfield, M. P.: Regional and global trends in sulfate aerosol since the 1980s, Geophys. Res. Lett., 34, L14803, doi:10.1029/2006g1028668, 2007.

Ministry of Agriculture of China (MAC): China Agriculture Yearbook 1997-2009, China Agriculture Press, Beijing, 1997-2009.

Ministry of Agriculture of India (MAI): Agriculture Statistics at a Glance 1996-2010, New Delhi, 1996-2010.

Ministry of Environmental Protection (MEP): Information on the mitigation of major pollutants in 2008, Beijing, China, 2009.

Ministry of Environmental Protection (MEP): Report on the state of the environment in China 2010, Beijing, 2011.

Mitra, A. P. and Sharma, C.: Indian aerosols: present status, Chemosphere, 49, 1175-1190, 2002.

National Bureau of Statistics (NBS): China Industry Economy Statistical Yearbook 1997-2010, China Statistics Press, Beijing, 1997-2010a.

National Bureau of Statistics (NBS): China Biweekly Economic Statistics 1997-2010, China Statistics Press, Beijing, 19972010b.

National Bureau of Statistics (NBS): China Monthly Statistics 1997-2010, China Statistics Press, Beijing, 1997-2010c.

National Bureau of Statistics (NBS): China Energy Statistical Yearbook 1997-2009, China Statistics Press, Beijing, 1998-2010.

National Bureau of Statistics (NBS): China County Statistical Yearbook 2000-2008, China Statistics Press, Beijing, 2001-2009.

National Institute for Public Health and the Environment: The IMAGE 2.2 implementation of the SRES scenarios [CD-ROM], Natl. Inst. Public Health Environ. Publ. 481508018, Bilthoven, The Netherlands, 2001.

Oak Ridge National Laboratory (ORNL): LandScan High Resolution Global Population Data Set, Oak Ridge National Laboratory, Oak Ridge, TN, USA, 2009.

Ohara, T., Akimoto, H., Kurokawa, J., Horii, N., Yamaji, K., Yan, X., and Hayasaka, T.: An Asian emission inventory of anthropogenic emission sources for the period 1980-2020, Atmos. Chem. Phys., 7, 4419-4444, doi:10.5194/acp-7-4419-2007, 2007.

Parashar, D. C., Gadi, R., Mandal, T. K., and Mitra, A. P.: Carbonaceous aerosol emissions from India, Atmos. Environ., 39, 7861-7871, 2005.

Patra, D. and Mishra, A. K.: Effect of sample geometry on synchronous fluorimetric analysis of petrol, diesel, kerosene and their mixtures at higher concentration, Analyst, 125, 1383-1386, 2000.

Prasad, A. K. and Singh, R. P.: Comparison of MISR-MODIS aerosol optical depth over the Indo-Gangetic basin during the winter and summer seasons (2000-2005), Remote Sens. Environ., 107, 109-119, 2007.

Ramanathan, V. and Carmichael, G.: Global and regional climate 
changes due to black carbon, Nat. Geosci., 1, 221-227, 2008.

Ramankutty, N. and Foley, J. A.: Estimating historical changes in global land cover: Croplands from 1700 to 1992, Global Biogeochem. Cy., 13, 997-1027, 1999.

Reddy, M. S. and Venkataraman, C.: Inventory of aerosol and sulphur dioxide emissions from India: I - Fossil fuel combustion, Atmos. Environ., 36, 677-697, 2002a.

Reddy, M. S. and Venkataraman, C.: Inventory of aerosol and sulphur dioxide emissions from India. Part II - biomass combustion, Atmos. Environ., 36, 699-712, 2002b.

Remer, L. A., Kaufman, Y. J., Tanre, D., Mattoo, S., Chu, D. A., Martins, J. V., Li, R. R., Ichoku, C., Levy, R. C., Kleidman, R. G., Eck, T. F., Vermote, E., and Holben, B. N.: The MODIS aerosol algorithm, products, and validation, J. Atmos. Sci., 62, 947-973, 2005.

Reserve Bank of India (RBI): Handbook of Statistics on the Indian Economy, Reserve Bank of India, Mumbai, India, 2010.

Russo, R. S., Talbot, R. W., Dibb, J. E., Scheuer, E., Seid, G., Jordan, C. E., Fuelberg, H. E., Sachse, G. W., Avery, M. A., Vay, S. A., Blake, D. R., Blake, N. J., Atlas, E., Fried, A., Sandholm, S. T., Tan, D., Singh, H. B., Snow, J., and Heikes, B. G.: Chemical composition of Asian continental outflow over the western Pacific: Results from Transport and Chemical Evolution over the Pacific (TRACE-P), J. Geophys. Res., 108, 8804, doi:10.1029/2002jd003184, 2003.

Sahai, S., Sharma, C., Singh, S. K., and Gupta, P. K.: Assessment of trace gases, carbon and nitrogen emissions from field burning of agricultural residues in India, Nutr. Cycl. Agroecosys., 89, 143$157,2010$.

Sahu, S. K., Beig, G., and Sharma, C.: Decadal growth of black carbon emissions in India, Geophys. Res. Lett., 35, L02807, doi:10.1029/2007g1032333, 2008.

Sinha, C. S., Sinha, S., and Joshi, V.: Energy use in the rural areas of India: Setting up a rural energy data base, Biomass Bioenerg., 14, 489-503, 1998.

Smith, S. J., Van Aardenne, J., Klimont, Z., Andres, R. J., Volke, A., and Delgado Arias, S.: Anthropogenic sulfur dioxide emissions: 1850-2005, Atmos. Chem. Phys., 11, 1101-1116, doi:10.5194/acp-11-1101-2011, 2011.

State Electricity Regulatory Commission (SERC): China Electric Power Yearbook 2001-2009, China Electric Power Press, Beijing, 2000-2009.

Streets, D. G., Tsai, N. Y., Akimoto, H., and Oka, K.: Sulfur dioxide emissions in Asia in the period 1985-1997, Atmos. Environ., 34, 4413-4424, 2000.

Streets, D. G., Gupta, S., Waldhoff, S. T., Wang, M. Q., Bond, T. C., and Bo, Y. Y.: Black carbon emissions in China, Atmos. Environ., 35, 4281-4296, 2001.

Streets, D. G., Bond, T. C., Carmichael, G. R., Fernandes, S. D., Fu, Q., He, D., Klimont, Z., Nelson, S. M., Tsai, N. Y., Wang, M. Q., Woo, J. H., and Yarber, K. F.: An inventory of gaseous and primary aerosol emissions in Asia in the year 2000, J. Geophys. Res., 108, 8809, doi:10.1029/2002jd003093, 2003.

Streets, D. G., Bond, T. C., Lee, T., and Jang, C.: On the future of carbonaceous aerosol emissions, J. Geophys. Res., 109, D24212, doi:10.1029/2004jd004902, 2004.

Streets, D. G., Wu, Y., and Chin, M.: Two-decadal aerosol trends as a likely explanation of the global dimming/brightening transition, Geophys. Res. Lett., 33, L15806, doi:10.1029/2006g1026471, 2006.

Streets, D. G., Yu, C., Wu, Y., Chin, M., Zhao, Z., Hayasaka, T., and Shi, G.: Aerosol trends over China, 1980-2000, Atmos. Res., 88, 174-182, 2008.

Streets, D. G., Yan, F., Chin, M., Diehl, T., Mahowald, N., Schultz, M., Wild, M., Wu, Y., and Yu, C.: Anthropogenic and natural contributions to regional trends in aerosol optical depth, 1980-2006, J. Geophys. Res., 114, D00D18, doi:10.1029/2008jd011624, 2009.

Tan, Q., Chameides, W. L., Streets, D., Wang, T., Xu, J., Bergin, M., and Woo, J.: An evaluation of TRACE-P emission inventories from China using a regional model and chemical measurements, J. Geophys. Res., 109, D22305, doi:10.1029/2004jd005071, 2004.

van der Werf, G. R., Randerson, J. T., Giglio, L., Collatz, G. J., Mu, M., Kasibhatla, P. S., Morton, D. C., DeFries, R. S., Jin, Y., and van Leeuwen, T. T.: Global fire emissions and the contribution of deforestation, savanna, forest, agricultural, and peat fires (19972009), Atmos. Chem. Phys., 10, 11707-11735, doi:10.5194/acp10-11707-2010, 2010.

van Donkelaar, A., Martin, R. V., Leaitch, W. R., Macdonald, A. M., Walker, T. W., Streets, D. G., Zhang, Q., Dunlea, E. J., Jimenez, J. L., Dibb, J. E., Huey, L. G., Weber, R., and Andreae, M. O.: Analysis of aircraft and satellite measurements from the Intercontinental Chemical Transport Experiment (INTEX-B) to quantify long-range transport of East Asian sulfur to Canada, Atmos. Chem. Phys., 8, 2999-3014, doi:10.5194/acp-8-2999-2008, 2008.

Venkataraman, C., Habib, G., Eiguren-Fernandez, A., Miguel, A. H., and Friedlander, S. K.: Residential biofuels in south Asia: Carbonaceous aerosol emissions and climate impacts, Science, 307, 1454-1456, 2005.

Venkataraman, C., Habib, G., Kadamba, D., Shrivastava, M., Leon, J. F., Crouzille, B., Boucher, O., and Streets, D. G.: Emissions from open biomass burning in India: Integrating the inventory approach with high-resolution Moderate Resolution Imaging Spectroradiometer (MODIS) active-fire and land cover data, Global Biogeochem. Cy., 20, GB2013, doi:10.1029/2005gb002547, 2006.

Wang, M., Huo, H., Johnson, L., and He, D.: Projection of Chinese motor vehicle growth, oil demand, and $\mathrm{CO}_{2}$ emissions through 2050, ANL/ESD/06-6, Argonne National Laboratory, Argonne, USA, 2006.

Wang, S., and Zhang, C.: Spatial and temporal distribution of air pollutant emissions from open burning of crop residues in China, China Science Paper Online (in Chinese), 3, 329-333, 2008.

Wang, Y., Hao, J., McElroy, M. B., Munger, J. W., Ma, H., Chen, D., and Nielsen, C. P.: Ozone air quality during the 2008 Beijing Olympics: effectiveness of emission restrictions, Atmos. Chem. Phys., 9, 5237-5251, doi:10.5194/acp-9-5237-2009, 2009.

Xu, Y., Williams, R. H., and Socolow, R. H.: China's rapid deployment of $\mathrm{SO}_{2}$ scrubbers, Energ. Environ. Sci., 2, 459-465, 2009.

$\mathrm{Xu}$, Y. A.: Improvements in the operation of $\mathrm{SO}_{2}$ scrubbers in China's coal power plants, Environ. Sci. Technol., 45, 380-385, 2011.

Yan, F., Winijkul, E., Jung, S., Bond, T. C., and Streets, D. G.: Global emission projections of particulate matter (PM): I. Exhaust emissions from on-road vehicles, Atmos. Environ., 45, 4830-4844, 2011. 
Yevich, R. and Logan, J. A.: An assessment of biofuel use and burning of agricultural waste in the developing world, Global Biogeochem. Cy., 17, 1095, doi:10.1029/2002GB001952, 2003.

Zhang, L. X., Yang, Z. F., Chen, B., Chen, G. Q., and Zhang, Y. Q.: Temporal and spatial variations of energy consumption in rural China, Commun. Nonlinear. Sci., 14, 4022-4031, 2009a.

Zhang, Q., Streets, D. G., Carmichael, G. R., He, K. B., Huo, H., Kannari, A., Klimont, Z., Park, I. S., Reddy, S., Fu, J. S., Chen, D., Duan, L., Lei, Y., Wang, I. T., and Yao, Z. L.: Asian emissions in 2006 for the NASA INTEX-B mission, Atmos. Chem. Phys., 9, 5131-5153, doi:10.5194/acp-9-5131-2009, 2009b.

Zhao, Y., Wang, S. X., Duan, L., Lei, Y., Cao, P. F., and Hao, J. M.: Primary air pollutant emissions of coal-fired power plants in China: Current status and future prediction, Atmos. Environ., 42, 8442-8452, 2008.
Zhao, Y., Duan, L., Xing, J., Larssen, T., Nielsen, C. P., and Hao, J. M.: Soil acidification in China: Is controlling $\mathrm{SO}_{2}$ emissions enough?, Environ. Sci. Technol., 43, 8021-8026, 2009.

Zhao, Y., Nielsen, C. P., Lei, Y., McElroy, M. B., and Hao, J.: Quantifying the uncertainties of a bottom-up emission inventory of anthropogenic atmospheric pollutants in China, Atmos. Chem. Phys., 11, 2295-2308, doi:10.5194/acp-11-2295-2011, 2011.

Zhi, G. R., Chen, Y. J., Feng, Y. L., Xiong, S. C., Li, J., Zhang, G., Sheng, G. Y., and Fu, J.: Emission characteristics of carbonaceous particles from various residential coal-stoves in China, Environ. Sci. Technol., 42, 3310-3315, 2008. 